\title{
Objects with symbolic meaning: 16 directions to inspire design for well-being
}

\section{Mafalda Casais*}

Department of Industrial Design,

Faculty of Industrial Design Engineering,

Delft Institute of Positive Design,

Delft University of Technology,

Delft, Netherlands

Email: m.casais@tudelft.nl

*Corresponding author

\section{Ruth Mugge}

Department of Product Innovation Management, Faculty of Industrial Design Engineering,

Delft University of Technology,

Delft, Netherlands

Email: r.mugge@tudelft.nl

\section{Pieter Desmet}

Department of Industrial Design,

Faculty of Industrial Design Engineering,

Delft Institute of Positive Design,

Delft University of Technology,

Delft, Netherlands

Email: p.m.a.desmet@tudelft.nl

\begin{abstract}
The symbolic meaning of a product can contribute to people's well-being. Previous research (Casais et al., 2016) has identified six distinct well-being enhancing symbolic meanings in products (based on Ryff, 1989): positive relations with others, personal growth, autonomy, environmental mastery, purpose in life, and self-acceptance. To support design activities with a focus on symbolic meaning, the current paper introduces 16 design directions that can be used for ideation and conceptualisation. These directions were developed in a two-stage process. First, 50 product examples were selected for their ability to encourage one or more of the six symbolic meanings. Second, these examples were used as stimuli in individual sessions with seven designers and design researchers. Participants analysed the product examples to infer the underlying design intentions, which were used to formulate the 16 symbolic meaning-focused 'design for subjective well-being' strategies.
\end{abstract}

Keywords: positive design; design directions; symbolic meaning; well-being.

Reference to this paper should be made as follows: Casais, M., Mugge, R. and Desmet, P. (2018) 'Objects with symbolic meaning: 16 directions to inspire design for well-being', J. Design Research, Vol. 16, Nos. 3/4, pp.247-281. 
Biographical notes: Mafalda Casais is a $\mathrm{PhD}$ candidate at the Department of Industrial Design Engineering, Faculty of Industrial Design Engineering, TU Delft, The Netherlands. Her research is being developed at the Delft Institute of Positive Design (http://www.diopd.org), focusing on the symbolic meaning of products, and its influence and contribution to subjective well-being of people. Her background includes illustration, graphic design, and product design.

Ruth Mugge is a Professor of Design for Sustainable Consumer Behaviour at the Department Product Innovation Management, Faculty of Industrial Design Engineering, TU Delft, The Netherlands. After finishing her Master's degree in Industrial Design Engineering, she completed a $\mathrm{PhD}$ project on the topic of product attachment. Her current research focuses on investigating how product appearance influences consumer response to products. She has published on these topics in several international journals.

Pieter Desmet is a Professor of Design for Experience at the Department of Industrial Design Engineering, Faculty of Industrial Design Engineering, TU Delft, The Netherlands. His main research interest is in understanding why and how design evokes emotion, and how design can contribute to the well-being of individual users and communities. He supervises a research group that studies various aspects of user experience, and chairs the 'Delft Institute of Positive Design' (see http://www.diopd.org). This institute aims to initiate and stimulate the development of knowledge that supports designers in their attempts to design for human flourishing. He is board-member of the International Design and Emotion society (see http://www.designandemotion.org), and has published over 80 scientific (journal) papers and book chapters; edited three books, three special issues, and two conference proceedings on a variety of aspects of experience-driven design.

This paper is a revised and expanded version of a paper entitled 'Extending product life by introducing symbolic meaning: an exploration of design strategies to support subjective well-being' presented at Product Lifetimes and the Environment (PLATE) Conference, Nottingham, 17-19 June, 2016.

\section{Introduction}

Consumer products can be repositories of personal symbolic meaning (e.g., Belk, 1988; Csikszentmihalyi and Rochberg-Halton, 1981; Wallendorf and Arnould, 1988). They can obtain their symbolic meaning when people associate them with meaningful or relevant experiences, people, places or ideas. For example, a proud mother may cherish her son's first sports medal, or a husband might be fond of a backpack that he took on his honeymoon. These are examples in which, through association, products have come to represent certain meaningful life experiences (Goodman et al., 2016; Yang et al., 2017). There are other ways in which products can obtain a symbolic meaning. For example, a product can symbolise a loved person, the relationship one has (or had) with them, or their life experiences. These are often products that belonged to the loved person. An example is an heirloom pocket watch that one's grandparents carried with them during the ordeals of wartime immigration and is now kept in the family. Such products may also represent aspirations or life goals. In contrast to the first two reasons, this symbolic meaning has a future rather than a past orientation. An example of this is the traditional 
Japanese Daruma doll, which is given as a gift to wish prosperity and encouragement, and used as a good luck talisman representing a person's life goals.

Various studies have explored the phenomenon of symbolic product meaning. Questions that have been addressed include: what makes a product meaningful (Friedmann and Lessig, 1986; Kleine and Kernan, 1988) and what kinds of meanings can products have (Dittmar, 1991; Fournier, 1991; McCracken, 1986; Richins, 1994). More recently, researchers have also started to explore the effects of symbolic meaning on consumer behaviour and experience. Symbolic meaning can prolong and valorise experiences (Love and Sheldon, 1998), and help people to relive or re-consume these experiences (Sääksjärvi et al., 2015). Mugge and colleagues (2008; 2009) found that symbolic meaning can stimulate product attachment, and that this attachment can motivate consumers to postpone product replacement. Related to these findings, several studies have explored how symbolic meaning can support 'emotional durability' (e.g., Chapman, 2005; van Nes and Cramer, 2005; Van Krieken et al., 2012). Symbolic meaning can also contribute to the consumer's subjective well-being (Pohlmeyer, 2012). In the field of 'positive psychology', subjective well-being is generally defined as a phenomenon with both cognitive and subjective components: a positive appreciation of one's life, a sense that one's life is good, meaningful and worthwhile, combined with the experience of joy, happiness, and contentment (Eid and Diener, 2004; Lyubomirsky, 2007; Veenhoven, 2011). Research in positive psychology has sought to devise and test positive interventions (e.g., activities) to support it (Boniwell, 2012; Snyder and Lopez, 2002). Products and their design can play a role in facilitating such activities and symbolising such meaningful experiences, thereby supporting subjective well-being (Abalada, 2014; Desmet, 2011; Escobar-Tello, 2016; Lacey, 2009; Ruitenberg and Desmet, 2012).

Casais et al. (2016) found six distinct symbolic meanings of everyday consumer products that can contribute to subjective well-being. These are symbolic meanings that represent and signify

1 positive relations

2 personal growth

3 purpose in life

4 environmental mastery

5 autonomy

6 self-acceptance (Casais et al., 2016; see Section 2 for a description).

To summarise, the body of research that has investigated the effects of symbolic meaning on consumer experience and behaviour indicates that products with symbolic meanings can help their owners to anticipate, encourage, preserve and prolong meaningful life experiences. In addition, these products can serve as reminders of such experiences and help people to relive and share them, which, in turn, can support consumer well-being. In our view, this represents an interesting opportunity for 'positive design', the field of research and practice that focuses on design for the well-being of individuals and communities (e.g., Corrigan-Doyle et al., 2016; Desmet and Hassenzahl, 2012; Desmet and Pohlmeyer, 2013; Petermans and Pohlmeyer, 2014). In the current paper, we aim to explore the possibility to develop design directions that can inspire designers when 
designing with well-being related symbolic meanings. While previous research has shown that symbolic meaning can contribute to a person's well-being and elicit attachment to products, it is not yet known if (and if so, how) products can be designed with the deliberate intention to support consumers in attributing such symbolic meanings, particularly with the aim of having a well-being effect.

As symbolic meaning is subjective, we do not expect to find one-to-one relationships between product features and associated meanings. A product's symbolic meaning is obtained in the personal consumer-product relationship and is determined by the person's situated experiences and the degree to which this person associates the product with these experiences. Essentially, any product can have any symbolic meaning. Something as simple as a paperclip can be cherished - perhaps it was used to bind the pages of someone's first contract as an independent consultant. In this example, it seems illogical to search for qualities of the paperclip design that contributed to the meaning formation. However, that does not imply that it is not possible to formulate design directions that can support designers in designing for symbolic meaning attribution. The challenge is similar to the one faced in the field of experience or emotional design (e.g., Desmet et al., 2016; Ozkaramanli and Desmet, 2012). Like symbolic meaning, emotions are subjective and cannot be designed directly. At the same time, a variety of useful tools are available to support designers in addressing the emotional impact of their designs. Rather than being prescriptive, these tools are inspirational. Some inform designers about the variety of emotions, the process of emotions, and manifestations of emotions (e.g., Yoon et al., 2016). Others can inspire by offering multiple examples of how products have evoked certain emotions in real-life experiences (e.g., Desmet, 2012; Fokkinga and Desmet, 2013; Huisman et al., 2013). Our current aim is similar. We report a study in which designers and design researchers analysed existing products in order to identify design directions. Here, we refer to design directions as 'directed plans of action' that can inform and inspire designers to include well-being related symbolic meaning in their design activities. The aim was to formulate a variety of diverse design directions that, as a collection, shed light on the variety of well-being related symbolic meanings and provide inspiration for addressing these meanings in creative idea generation. The study resulted in 16 design directions, which we will describe and discuss below. In the general discussion, we reflect on the implications of this study for the field of positive design.

\section{Method}

In a previous study, we found that consumer products can support subjective well-being with at least six symbolic meanings (Casais et al., 2016). These symbolic meanings represent the determinants of psychological well-being that were formulated by Ryff (1989):

1 Positive relations with others: products that symbolise meaningful and reciprocal relations and affiliations that provide a sense of belongingness.

2 Personal growth: products that symbolise acceptance of past experiences or openness to new challenges, which afford a sense of maturity and development.

3 Purpose in life: products that symbolise personally significant goals that give a sense of purpose and direction in life. 
4 Environmental mastery: products that symbolise social thriving and the ability to build a context that is suitable for personal needs and values.

5 Autonomy: products that symbolise self-reliance in thought and action, and a sense of authenticity.

6 Self-acceptance: products that symbolise self-compassion and a positive self-image.

To explore which design directions can embody these six meanings, 50 existing products were analysed. First, 50 products were selected that were interpreted (by design researchers with expertise in well-being) as having the ability to support one or more of the six symbolic meanings. Next, in individual sessions, these products were discussed with seven designers and design researchers. They were asked to categorise and analyse each product. They reflected on the relationship between the designs and the symbolic meanings, hypothesised what design decisions may have supported that relationship, and, based on these considerations, formulated design directions.

Table 1 Profiles of two sets of experts who collected and selected the product examples (each expert code refers to a different individual)

\begin{tabular}{|c|c|c|c|c|c|c|}
\hline $\begin{array}{l}\text { Stage of stimuli } \\
\text { preparation }\end{array}$ & Code & Qualification & (*) Age & Gender & Role & $\begin{array}{l}\text { (*) Refereed } \\
\text { publications }\end{array}$ \\
\hline \multirow[t]{3}{*}{$\begin{array}{l}\text { Initial } \\
\text { collection of } \\
100 \text { product } \\
\text { examples }\end{array}$} & EX01 & $\begin{array}{c}\text { PhD in Industrial } \\
\text { Design Engineering }\end{array}$ & 42 & Male & $\begin{array}{l}\text { Professor in design } \\
\text { for experience; } \\
\text { researcher in } \\
\text { design for emotion } \\
\text { and positive design }\end{array}$ & 125 \\
\hline & EX02 & $\begin{array}{l}\mathrm{PhD} \text { in Industrial } \\
\text { Design Engineering }\end{array}$ & 37 & Female & $\begin{array}{l}\text { Associate } \\
\text { professor in } \\
\text { consumer research; } \\
\text { researcher in } \\
\text { product attachment }\end{array}$ & 55 \\
\hline & EX03 & $\begin{array}{l}\text { MSc in Product } \\
\text { Design }\end{array}$ & 30 & Female & $\begin{array}{l}\text { Design researcher } \\
\text { in positive design }\end{array}$ & 4 \\
\hline \multirow{4}{*}{$\begin{array}{l}\text { Selection of } 50 \\
\text { product } \\
\text { examples to be } \\
\text { used as stimuli } \\
\text { in the study }\end{array}$} & EX04 & $\begin{array}{l}\text { MSc in Industrial } \\
\text { Design Engineering } \\
\text { (design for } \\
\text { interaction) }\end{array}$ & 31 & Male & $\begin{array}{l}\text { Researcher in } \\
\text { design for rich } \\
\text { experiences }\end{array}$ & 12 \\
\hline & EX05 & $\begin{array}{l}\text { MSc in Industrial } \\
\text { Design Engineering } \\
\text { (design for } \\
\text { interaction) }\end{array}$ & 30 & Female & $\begin{array}{l}\text { Researcher in } \\
\text { design for } \\
\text { dilemmas }\end{array}$ & 6 \\
\hline & EX06 & $\begin{array}{l}\text { MSc in Industrial } \\
\text { Design Engineering } \\
\text { (design for } \\
\text { interaction) }\end{array}$ & 35 & Male & $\begin{array}{l}\text { Researcher in } \\
\text { design for } \\
\text { emotional } \\
\text { granularity }\end{array}$ & 6 \\
\hline & EX07 & $\begin{array}{l}\text { MA in Creative } \\
\text { Industries Design }\end{array}$ & 27 & Female & $\begin{array}{l}\text { Researcher in } \\
\text { design for loss }\end{array}$ & 1 \\
\hline
\end{tabular}

Notes: $(*)$ At the moment the study took place. 


\subsection{Stimuli collection}

In order to select the 50 product examples used in the study, three expert researchers (see Table 1) collected 100 product examples that were considered examples to which, in our view, well-being related symbolic meaning could be attributed.

Potentially, any product can gain symbolic meaning through its evolving relationship with the user. However, in this procedure we were looking for products that seem to have been designed specifically with the well-being effect in mind Our goal in the stimuli collection phase was to gather product examples that, in our view, are likely candidates for the attribution of well-being related symbolic meaning, i.e., designed to facilitate the attribution of this kind of meaning.

The sources for images and descriptions were well-established online design blogs, such as Dezeen (http://www.dezeen.com), Design Milk (http://design-milk.com), Yanko Design (http://www.yankodesign.com), Core 77 (http://www.core77.com) and Mocoloco (http://mocoloco.com). From the blog posts, we retrieved, as much as possible, objective descriptions about the product, avoiding opinions or subjective remarks. To find relevant products, meaning-related keywords were used, such as the six symbolic meanings and other descriptors like 'symbolic meaning', 'sentimental value', 'cherished possessions', and 'meaningful interactions'. Furthermore, specific types of meaningful possessions were used as search keywords, such as 'heirlooms' and 'souvenirs' (for the complete list of keywords see Annex).

\subsection{Stimuli selection}

The collection of 100 items was narrowed down to a manageable size by selecting those with the closest links to well-being related symbolic meaning. This was done in a one-hour session with four design researchers with expertise in positive design (see Table 1). A set of 100 stimuli cards was printed, each card depicting one of the symbolically meaningful product examples. The cards measured about 10 by 5 centimetres, and featured a photograph or concept image, information about the product, the name and designer of the product, and sources of image and text (Figure 1). The images were selected in order to be as clear as possible (e.g., in use, as a standalone), thereby making it quick and easy to understand the product example.

The experts were instructed to select 50 symbolically meaningful products, based on the six symbolic meanings, which were introduced at the beginning of the session. Specifically, they were requested to read the product descriptions and infer their effect on people's subjective well-being. The experts were instructed to consider the products' ability to be a likely candidate for symbolic meaning attribution, which potentially could have a well-being effect. Initially the choice was individual, in three piles of 'yes', 'no' and 'maybe' respectively, followed by a discussion on the final collective selection. Examples of quotes retrieved from the discussion referring to the ability of a product to be a likely candidate for symbolic meaning attribution are: "The user has to do something with it in order for it to work, and also the user is left to use his or her imagination. I would say this is meaningful because every time you see it, you also see something that you did with it and it makes it personal" (EX04); "Some objects don't connect to six symbolic meanings because they are meaningful universally. However, this one has the "self" element. It's about self-development" (EX05). "There are these kind of 
communication devices that intentionally restrict how people communicate. It's about making it somehow poetic, and that's what makes it meaningful"' (EX04).

Figure 1 Examples of stimuli cards used in the study (see online version for colours)
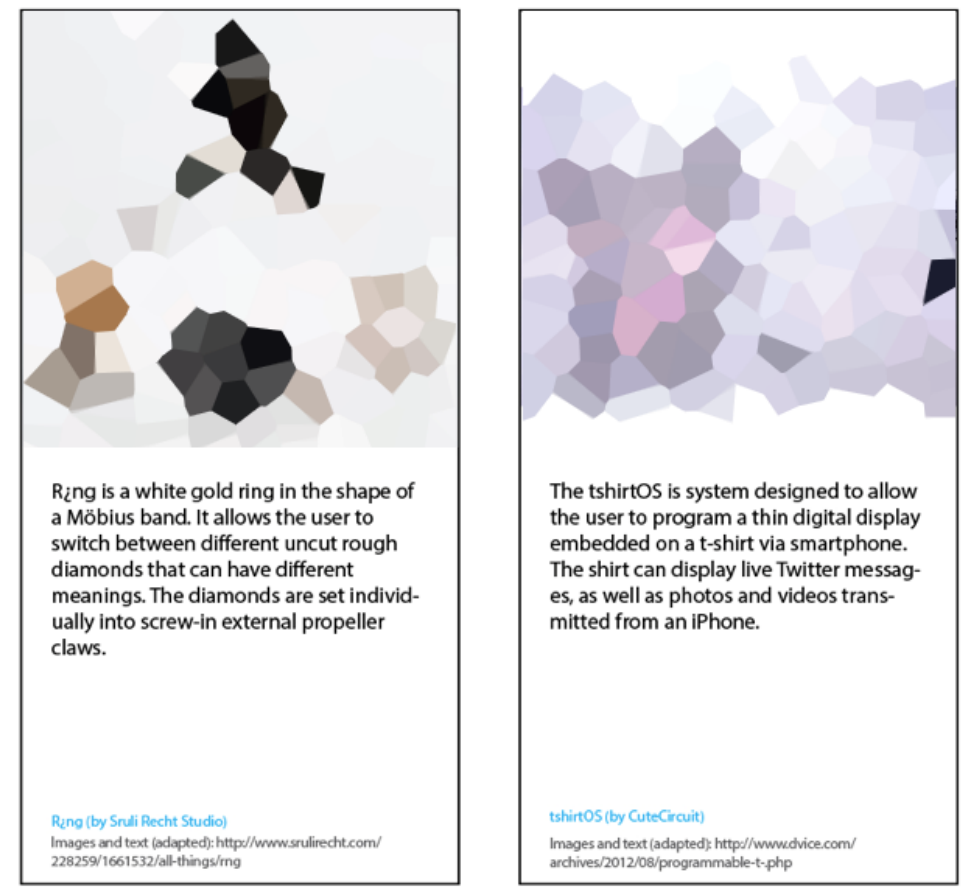

Note: The images are pixelated for copyright purposes.

Following the discussion, the experts were able to reach consensus easily and quickly. All six symbolic meanings were taken into account in the product selection. The final selection of 50 stimuli with the respective descriptions can be found online: http://symbolicmeaningresearch.weebly.com.

\subsection{Participants}

Following the stimuli selection phase, seven participants joined the study. Four of them were design researchers and three were designers (see Table 2). The main criterion for selecting participants was that they had to have sufficient experience with product design (having at least a bachelor degree in industrial design). Recruiting both designers and design researchers as participants aimed to bring both a practical and a reflective perspective on the study. A pilot session was conducted beforehand to refine the study procedure.

\subsection{Procedure}

The study was conducted in individual sessions, which were structured in two parts (taking on average 3 hours and 50 minutes), preceded by an introduction to the research and the well-being related symbolic meanings: part 1 , the categorisation of product 
examples in the meaning categories; and part 2, the analysis of the resulting groups and exploration of potential design strategies, and elaboration of specific meaning-driven design directions. To keep the tasks feasible for the participants, the study was split into two sessions held on different days, the first dedicated to the categorisation of product examples, and the second to the analysis and formulation of design directions.

Table 2 Profile of participants

\begin{tabular}{|c|c|c|c|c|c|}
\hline Code & Qualification & Age & Gender & $\begin{array}{l}\text { Years of experience } \\
\text { in design }\end{array}$ & Role/field of work \\
\hline DRP01 & MSc in Product Design & 29 & Female & 11 & $\begin{array}{l}\text { Design researcher in } \\
\text { the field of design } \\
\text { methodology }\end{array}$ \\
\hline DP02 & $\begin{array}{l}\text { MSc in Industrial Design } \\
\text { Engineering (design for } \\
\text { interaction) }\end{array}$ & 27 & Male & 10 & User-centred designer \\
\hline DRP03 & $\begin{array}{l}\text { MSc in Industrial Design } \\
\text { Engineering (design for } \\
\text { interaction) }\end{array}$ & 30 & Female & 12 & $\begin{array}{c}\text { Design researcher in } \\
\text { the field of positive } \\
\text { design }\end{array}$ \\
\hline DP04 & $\begin{array}{l}\text { MSc in Industrial Design } \\
\text { Engineering (integrated } \\
\text { product design) }\end{array}$ & 29 & Male & 11 & Industrial designer \\
\hline DRP05 & MSc in Design & 31 & Male & 12 & $\begin{array}{l}\text { Design researcher in } \\
\text { the field of design for } \\
\text { sustainability }\end{array}$ \\
\hline DP06 & $\begin{array}{l}\text { Bachelor in Engineering } \\
\text { (industrial product design) }\end{array}$ & 35 & Male & 8 & Industrial designer \\
\hline DRP07 & $\begin{array}{l}\text { MSc in Industrial Design } \\
\text { Engineering (design for } \\
\text { interaction) }\end{array}$ & 29 & Female & 10 & $\begin{array}{l}\text { Design researcher in } \\
\text { the field of co-design }\end{array}$ \\
\hline
\end{tabular}

Notes: $\mathrm{DRP}=$ design researcher; $\mathrm{DP}=$ designer, each participant code refers to a different individual.

Three days before the study, all participants received the selection of 50 product examples in the form of stimuli cards. Each card contained a photograph or concept image of the product and textual information (see Figure 1). Participants were sent the designs before the session to provide them with sufficient time to familiarise themselves with the designs. They were instructed to take some time (as much as they needed) to get acquainted with the designs by looking at the pictures and reading the descriptions on the cards. We decided to include this step in the procedure because we expected that the participants would feel overwhelmed if we asked them to get acquainted with the designs at the start of the session.

During the introduction (approximately 25-30 minutes) the researcher explained the framework of six symbolic meanings, and provided a short summary of each category for the participant to read, including examples of stories of meaningful products for each symbolic meaning (Casais et al., 2016). The framework categories were presented in the form of cards (in a similar format as the product example cards) to provide the participant with a visual reminder of the symbolic meanings.

Next, the 50 product example cards were provided, and the participant was instructed to go through them and check if all examples were clear, and to indicate anything they 
found ambiguous. This lasted for about 10 minutes. Subsequently, the participant categorised the products using the six well-being related symbolic meanings. The participant was instructed to divide the product examples into the six categories quickly and intuitively, while vocalising his/her thoughts, and to use post-it notes to indicate examples that fit multiple categories. At this point, the participant was reminded not to fixate on specific features of the product examples, and instructed to focus on the essence of the designs. The categorisation task lasted approximately 1 to 2 hours.

Following the categorisation task, the participant engaged in exploring and uncovering preliminary 'design for well-being' directions. This lasted approximately 2 to 3 hours. Specifically, the participant was instructed to explore each group of categorised product examples, inferring the intended strategy behind each product or group. Once more, the participant was encouraged to vocalise his/her thought process, and to write keywords and possible strategies embodied in the products using post-it notes. During the categorisation and analysis exercises, participants intuitively created sub-groups according to the general approaches of the products in terms of symbolic meaning. Once all the categorised groups were analysed, the participant paired similar approaches into better-defined, potentially promising design directions and identified multiple examples to illustrate them.

\subsection{Data analysis}

The sessions were recorded with video and photos. The tasks were conducted thoroughly, and the participants seemed satisfied when they had finished; each generated 10 to 30 design directions. The produced design directions were analysed using the 'Gioia methodology' (Gioia et al., 2012) because it offers a well-guided generative analytical procedure. This methodology, which is based on the idea that qualitative data can be rigorous and systematic in the generation of new ideas, proposes three steps: grouping direct quotes from participants in first-order 'informant-centric' descriptions, organising them into second-order 'research-centred' themes, and refining these into new concepts. It has been used in several studies, mostly in the fields of administration, management and human relations (for an overview of examples, see Gioia et al., 2012).

An example of the analysis of a product is presented (Table 3) and explained below. In this example, participants discussed a product and tried to infer a possible underlying design strategy by analysing its features and affordances, its commercial promises, and its potential effects on the owner's well-being. The result is a strategy that can be used in other product typologies with the aim of producing a certain effect.

For the analysis, participants' descriptions of preliminary design directions on post-it notes were used as units of analysis, and audio recordings were used as a complementary source to clarify any ambiguity. These 'first-order' descriptions (using participant-based terms) were combined according to their semantic similarity and simplified while still preserving the core meaning intended by participants. The first-order descriptions were then abstracted into 'second-order' themes (using terms and concepts constructed by the researchers) that aimed to better outline clear and usable design directions. This process was conducted in an iterative way and by simultaneously considering all the participant descriptions, to ensure that data saturation had been reached, that is, to ensure that all possible themes were generated, and that they were not ambiguous or likely to be divided into new or sub-directions. Lastly, the themes were narrowed down to one or more well-defined and clear design directions. 
Table 3 Example of the analytical process of one product

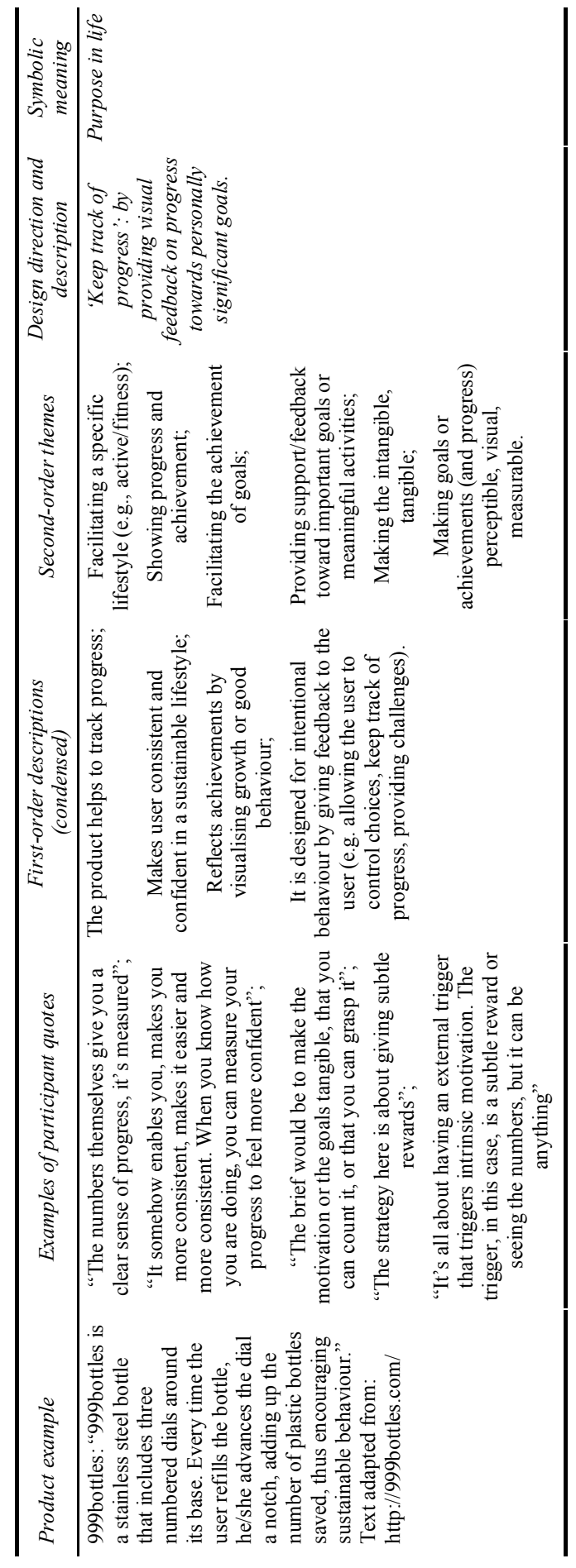




\section{Results}

In total, the coding process resulted in 16 design directions (Table 4).

Table 4 Summary of the resulting design directions

\begin{tabular}{|c|c|c|}
\hline Symbolic meaning & Design direction & Description \\
\hline \multirow[t]{2}{*}{$\begin{array}{l}\text { Positive relations } \\
\text { with others }\end{array}$} & $\begin{array}{l}\text { Support meaningful } \\
\text { affiliations }\end{array}$ & $\begin{array}{l}\text { By facilitating the practice of } \\
\text { group/community activities }\end{array}$ \\
\hline & $\begin{array}{c}\text { Embody characteristics } \\
\text { of a group }\end{array}$ & $\begin{array}{l}\text { By using unique characteristics of the groups } \\
\text { the user belongs to (e.g., culture, profession) }\end{array}$ \\
\hline \multirow[t]{4}{*}{ Personal growth } & $\begin{array}{c}\text { Support active personal } \\
\text { development }\end{array}$ & $\begin{array}{l}\text { By providing a platform for active reflection } \\
\text { on lessons learned and future expectations }\end{array}$ \\
\hline & $\begin{array}{l}\text { Embody personal } \\
\text { growth }\end{array}$ & $\begin{array}{l}\text { By focusing on adaptability to accommodate } \\
\text { physical and/or psychological change }\end{array}$ \\
\hline & $\begin{array}{l}\text { Support acceptance and } \\
\text { growth from past } \\
\text { experiences }\end{array}$ & $\begin{array}{l}\text { By providing a tangible representation of the } \\
\text { passage of time }\end{array}$ \\
\hline & Enhance memories & $\begin{array}{l}\text { By offering a positive context or activity to } \\
\text { reflect on memories of loved ones }\end{array}$ \\
\hline \multirow[t]{3}{*}{ Purpose in life } & $\begin{array}{l}\text { Encourage positive } \\
\text { change }\end{array}$ & $\begin{array}{c}\text { By providing an external trigger that suggests } \\
\text { beneficial activities or behaviours }\end{array}$ \\
\hline & $\begin{array}{l}\text { Provide a sense of } \\
\text { control }\end{array}$ & $\begin{array}{c}\text { By allowing the user to manage personally } \\
\text { significant goals, or to eliminate obstacles in } \\
\text { their fulfilment }\end{array}$ \\
\hline & Keep track of progress & $\begin{array}{l}\text { By providing visual feedback on progress } \\
\text { towards personally significant goals }\end{array}$ \\
\hline \multirow[t]{2}{*}{$\begin{array}{l}\text { Environmental } \\
\text { mastery }\end{array}$} & $\begin{array}{l}\text { Support multi-sensorial } \\
\text { communication }\end{array}$ & $\begin{array}{c}\text { By translating messages into a sensorial } \\
\text { experience }\end{array}$ \\
\hline & $\begin{array}{l}\text { Provide a context for } \\
\text { meaningful interaction }\end{array}$ & $\begin{array}{l}\text { By making use of the context or limitations as } \\
\text { an advantage }\end{array}$ \\
\hline \multirow[t]{3}{*}{ Autonomy } & Destigmatise & $\begin{array}{l}\text { By enhancing the aesthetic qualities of } \\
\text { physically enabling products }\end{array}$ \\
\hline & Design for mindfulness & $\begin{array}{l}\text { By slowing down processes or disclosing } \\
\text { mechanisms behind products to promote } \\
\text { mindful living }\end{array}$ \\
\hline & $\begin{array}{l}\text { Redirect the user's } \\
\text { attention }\end{array}$ & $\begin{array}{l}\text { By designing an intervention that requires } \\
\text { attention from the user to distract from } \\
\text { negative situations }\end{array}$ \\
\hline \multirow[t]{2}{*}{ Self-acceptance } & $\begin{array}{l}\text { Allow shared } \\
\text { transformation }\end{array}$ & $\begin{array}{l}\text { By providing tools for user input at an } \\
\text { aesthetic and/or functional level }\end{array}$ \\
\hline & Allow self-expression & $\begin{array}{l}\text { By providing a tangible platform to wear, } \\
\text { share or display personally significant ideas }\end{array}$ \\
\hline
\end{tabular}

\section{Discussion}

In this section, the design directions are explained and illustrated with product examples, and their potential effects are discussed along with the relevant literature. 


\subsection{Design directions for the symbolic meaning of positive relations with others}

The symbolic meaning of positive relations with others symbolises quality relations and affiliations that contribute to a sense of belongingness. Two of the resulting design directions aim to trigger this symbolic meaning:

1 support meaningful affiliations

2 embody characteristics of a group.

\subsubsection{Support meaningful affiliations}

The design direction 'support meaningful affiliations' can be concretised by facilitating the practice of group or community activities. It suggests that by making such practices more accessible, a product can gain the value of belongingness and thus support subjective well-being. The proposed design direction relates to the desire to form social attachments and to feel inclusion, which is linked to a fundamental human need for belongingness (Baumeister and Leary, 1995). This sense of belongingness can be supported in different ways: for example, through group or community activities in which there is a recognition of membership, or through activities associated with belief and spirituality, which do not necessarily imply the physical presence of a group, but still support the sense of feeling part of something bigger than the self (Mehta and Belk, 1991; Widman et al., 2009).

A product that provides guidance and simplifies or provides easier access to group or community activities can encourage a person to cultivate such meaningful affiliations and is thus conducive to gaining a symbolic meaning related to those positive relations, provided that the activity the product facilitates and the group it represents are of emotional relevance to the person.

Figure 2 EL Sajjadah by SOPDS (see online version for colours)

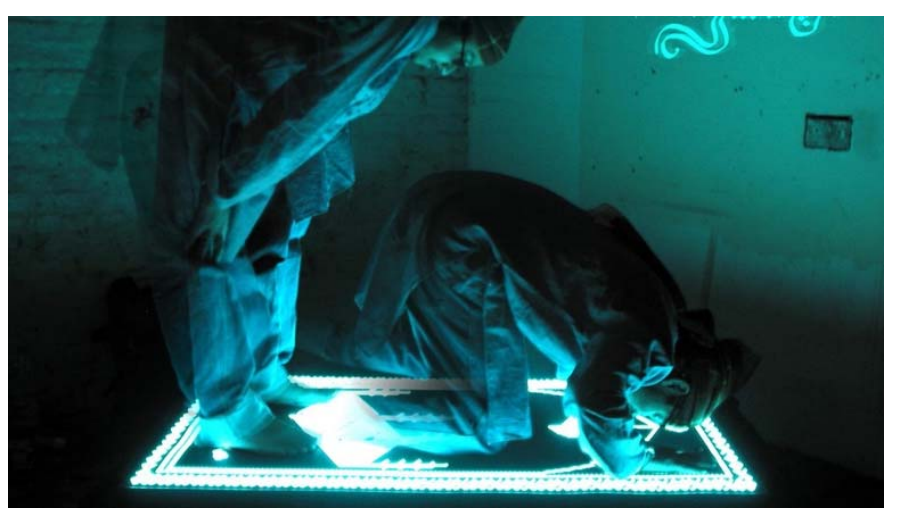

Note: Reprinted with permission.

An example of a product that can illustrate this design direction is the EL Sajjadah, designed by Soner Ozenc (Soner Ozenc Product Design Studio) (Figure 2). This product supports meaningful affiliations by facilitating the practice of community activities. It is an electroluminescent praying carpet with a built-in compass. The carpet lights up when facing Mecca, and recreates the atmosphere of a mosque through light and printed 
patterns. Study participants identified the potential of the (inferred) design strategy of this product in the following way: "It is an enabler for personally significant values or goals. In this case, religion is a value, it's a big value and it's also a goal that you want to obey, so you do things that make you part of that religion" (DRP03). "You belong to a group, and the product is allowing you to perform the activity that relates you to a group" (DP02).

\subsubsection{Embody characteristics of a group}

The design direction 'embody characteristics of a group' can be manifested by making use of unique features of meaningful groups a person belongs to (e.g., culture, profession). It suggests that by using familiar references that reflect social identity, a product can gain a symbolic meaning to the person and thus support their subjective well-being. Like the previous design direction, it relates to the human need for belongingness. Moreover, it builds on the idea that products have an important role in symbolising group affiliations, and in the construction and communication of social identity (Belk, 1988; Ledgerwood et al., 2007). When considering this design direction, designers can, for example, focus on specific features of a culture's craftsmanship and folklore, on institutional imagery and subculture imagery, or even on personal characteristics (like being left-handed) to generate identification with a product and increase its value to the consumer. An example of this is the El Botijo (see http://www.monicathurne.com/?/projects/elBotijo), designed by Monica Thurne and Mariana Lerma (Wowqstudio Design Collective). This product is a water container made of unglazed ceramics that cools water without refrigeration, even in warm weather. It is a redesign of the traditional Spanish water container, keeping its materials and function. Besides being a functional product, this vessel can be seen as a material repository for traditional artefact production techniques and social practices, and embodies group characteristics of Mediterranean culture. Study participants mentioned the potential of this design direction when referring to El Botijo: "The material is used to portray a culture. It portrays the art that has been there for ages. The function even is indicative of a culture" (DRP01). "It's about taking a cultural reference to make it into something that you can carry, you can have with you as a part of your identity" (DP02).

This design direction is linked to the idea that consumer goods have deep cultural meanings (McCracken, 1986) and that using cultural references in design is a way to preserve the heritage of people and extend it to other contexts (Lin, 2007). Furthermore, having a sense of belonging to one's community has been found in previous research to be a strong predictor of well-being (Leung et al., 2011). A product that symbolises such meaningful affiliations can remind a person of that kinship or membership and encourage feelings of belongingness, thereby supporting their subjective well-being.

\subsection{Design directions for the symbolic meaning of personal growth}

The symbolic meaning of personal growth symbolises the acceptance of past experiences, openness to new challenges, continued development and maturity. Four of the resulting design directions aim to trigger this symbolic meaning:

1 support active personal development

2 embody personal growth 
3 support acceptance and growth from past experiences

4 enhance memories.

\subsubsection{Support active personal development}

The design direction 'support active personal development' can be adopted by providing a platform for active reflection on lessons learned and future expectations. Such reflection activities, manifested in the form of diary-keeping, for example, have been shown to relieve stress and anxiety (Burt, 1994) and hold high transitional value (Sosin, 1983). The proposed design direction suggests that products that assist with personal reflection practices can gain an important symbolic meaning to the person, because they provide an intimate overview of their life: these products support the reminiscence of personal achievements, the contemplation of past experiences, and the projection of personal goals, thereby supporting well-being. Reflective practices - including reflecting on negative past events, mediated by tools (e.g., writing exercises), products or technology (interactive systems, social media, etc.) - have been show to result in increased well-being (Isaacs et al., 2013; Mols et al., 2017). To illustrate this, an example of a product that supports active personal development by providing a platform for reflection is the OWL - on the wisdom of life, designed by Elger Oberwelz and Yusuke Miyashita (Designs On/IDEO). It is a wall-mounted 'time capsule' that contains 80 tubes, representing the years in a person's life (Figure 3). Each year, the owner writes a reflection on the past year (placing it on the top row, visually representing the ups and downs) and a wish for the coming one (on the bottom row). This product also allows the whole family to participate in reflection on personal development, helping members to share their accomplishments and hopes. In the study, participants identified the potential of this design direction in OWL in the following way: "It has a component of self, but that may have nothing to do with having achieved important goals, actually, if you had failed in all your goals, this would still be about self-development" (DRP03). "You can specifically see the growth, or read it" (DP04). "It enables the process of reflecting on past and future experiences, it provides a deliberate action to reflect, a mindful reflection action" (DRP01).

Figure 3 OWL - on the wisdom of life by Designs on/IDEO (see online version for colours)

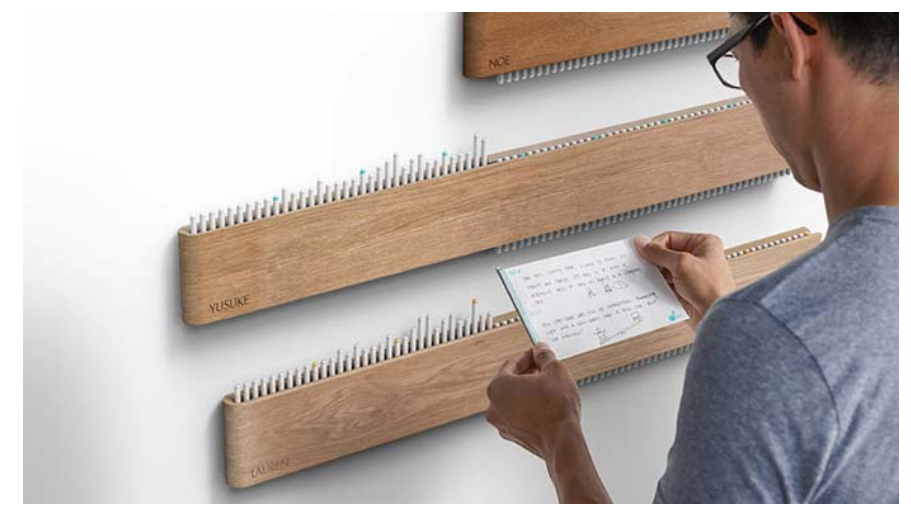

Note: Image courtesy of IDEO, reprinted with permission. 


\subsubsection{Embody personal growth}

The design direction 'embody personal growth' can be applied by focusing on adaptability to accommodate physical and psychological change, stimulating intentional behaviour of the user and the will to mature and develop further.

When people grow older, their bodies change. When people go through certain life milestones, their ideas about the world and themselves change. Change is an inherent and desirable part of growth and development, because it is by adapting to new realities that people can thrive. Acknowledging and accepting change bolsters maturity, which has been shown to support well-being (Sheldon and Kasser, 2001). Furthermore, research on well-being has shown that reflecting on one's growth is not only a habit of happy individuals, but is also prescribed as a well-being enhancing exercise (Lyubomirsky, 2007; Lyubomirsky and Kurtz, 2008). A product that visualises change and personal growth may assist in such reflective practices. Products that allow a visual overview on personal growth can, by association, become valuable to the person and stimulate further growth, supporting the person's sense of accomplishment. An example of a product that embodies personal growth by focusing on adaptability to accommodate physical and psychological change is the Weight Recorder designed by Wu Weiche (Weiche Design Works) (Figure 4). It is a weight chart that pregnant women can use to record their changing weight by drawing on a disk that can be preserved. It relates to the symbolic meaning of personal growth because it adapts to changes and records them, creating a tangible representation of physical and emotional experiences and thereby has the potential to gain symbolic meaning and support well-being. Participants in the study have discussed the product's potential to support subjective well-being through this design direction: "The product shows progress on something personal that is life changing" (DP06). "It has an emotional connotation, but it is about emotional growth, embodying self-growth" (DRP03). "It is making it tangible, making the self-development of that person tangible, making the transition into something perceptible" (DP02).

Figure 4 The weight recorder by Weiche Design Works (see online version for colours)

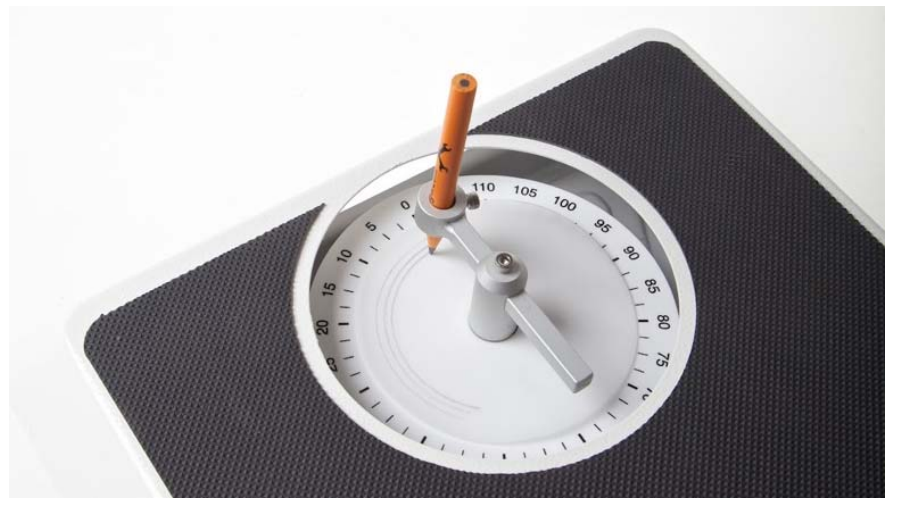

Note: Reprinted with permission.

\subsubsection{Support acceptance and growth from past experiences}

The design direction 'support acceptance and growth from past experiences' can be expressed by providing a physical representation of the passage of time that embodies 
and offers an overview of past occurrences, events, thoughts, actions, or experiences that have supported a person's development and maturity. To create a representation of time that is relevant for the target group, designers can consider different time scales to suit different people, and create metaphors that reflect those differences. Using metaphors can be a way for designers to create products that people find compelling (Hekkert and Cila, 2015).

This design direction suggests that having a physical reminder of the past year can help a person come to terms with positive and negative events. This object thereby gains a symbolic meaning related to maturity and growth and thus supports subjective well-being. For example, designer Siren Wilhelmsen developed the 365 knitting clock, a 24-hour clock that produces a scarf over the course of a year to show the nature of time in a different manner (see http://www.sirenelisewilhelmsen.com/work.html). It knits one complete circle of stitches every day and displays the time by the position of the thread. The incomplete scarf hangs from the clock, representing the time that has passed, and the ball of yarn represents the amount of time left in the year. After 365 days, the two-metre scarf is ready to be worn. By metaphorically carrying the previous year with them in the form of a scarf, the person also carries the good and bad experiences that happened in that time. A very positive year can be worn with pride and confidence, whereas a negative year can be a reminder of perseverance and strength. In the long term, certain special years may be kept and worn to remember important moments. Past research has shown that reflective practices have a positive effect on health (both physical and mental, particularly in respect to depression and anxiety) (Frisina et al., 2004). Even when the reflection is on negative events it can have positive results (Wilson and Gilbert, 2008). Participants identified the potential of the design direction through their discussion of the 365 knitting clock: "It shows the passing of time. The generic clock tells you the time that it is now, this shows the time that has passed" (DP04). "It's a passive kind of reflection" (DRP01). "It takes this symbol, the very common concept of time, as the element. It's about emotional self-growth that applies to everyone" (DRP03).

\subsubsection{Enhance memories}

The design direction 'enhance memories' can be concretised by offering a positive context or activity to reflect on memories of loved ones. While also promoting the association with the symbolic meaning of positive relations with others, this design direction is closer to the symbolic meaning of personal growth due to the encouragement of reminiscence and reflection on memories linked to those relationships. Reminiscence the ability to recollect good things - can be used as a form of therapy. Previous research has reported that reminiscence therapy can improve socialisation, promote a sense of accomplishment and decrease symptoms of depression (e.g., Bohlmeijer, 2007; Chiang et al., 2010). Activities of reminiscence therapy include sharing memories and life stories, recalling family history and positive relationships, and recalling transition moments and milestones. Products can enable immersive experiences that assist people in revisiting the impact of their memories (and enhance them) rather than in recalling objective circumstances of their past (i.e., merely pointing out objective information). This, in turn, can influence personal judgements about one's past and trigger a symbolic meaning linked to personal growth, which can support subjective well-being.

One product that exemplifies this design direction is the Heirloom, by designer Nikki George Ferguson (see http://design-milk.com/the-heirloom-by-nikki-george-ferguson). 
The Heirloom enhances memories by offering an activity to remember and reflect on memories of loved ones. It is a device that allows a person to display a sentimental object of their own, and to record thoughts and stories about it so that it can be passed down to the next generation. While admiring the object, the receiver/listener can turn the Heirloom dial to hear the voice of the loved one telling their story or a memory related to the object. This serves to encourage family members and loved ones to consider not only the way they saw and knew the owner and the object, but also to imagine how these memories will last beyond their own lifetime. Study participants discussed the potential of the product regarding the design direction in the following way: "This is something you want to go back on, something to treasure. It gives you an emotional moment with this memory" (DP06). "It creates a personal bridge between the past and the future through a personal object" (DP04). "The product is giving you this level of deepness. It's not like looking at a photo, it's closer to the idea of video. It's about the level of feeling you can have from a product" (DRP05).

\subsection{Design directions for the symbolic meaning of purpose in life}

The symbolic meaning of purpose in life symbolises personally significant goals and aspirations, and a sense of directedness. Three of the resulting design directions aim to trigger this symbolic meaning:

1 encourage positive change

2 provide a sense of control

3 keep track of progress.

\subsubsection{Encourage positive change}

The design direction 'encourage positive change' can be put in practice by providing an external trigger that encourages beneficial activities or behaviours. A product that gives agency to a person to determine his or her personally meaningful goals in a simplified way, and also provides room for the person to determine whether he or she is able and willing to pursue them, is more likely to be effective (Ruitenberg and Desmet, 2012). This design direction proposes that a product can be a catalyst that encourages a person to take positive action by providing personally meaningful feed-forward. Moreover, by symbolising a desired behavioural change, a product can gain symbolic meaning to a person. Past research has shown that setting specific goals increases motivation and encourages a positive attitude towards the tasks it involves (Bryan and Locke, 1967). Furthermore, personal beliefs about willpower and one's ability to succeed have been shown to influence one's well-being (Bernecker et al., 2017). Therefore, incorporating a visual component into goal pursuit - which can be made tangible by a product - increases the chance of success, which in turn fosters subjective well-being.

An example of a product that encourages positive change by providing an external trigger is the Blank Wall Clock by designer Martí Guixé (Alessi). The Blank Wall Clock provides a blank surface with white hour and minute hands, and allows the user to assign an idea to each hour by writing it down with a whiteboard marker (Figure 5). The uniqueness of the ideas people write down can elicit a very personal and powerful effect. When these align with personally meaningful wishes, dreams, or goals, the product 
becomes a source of inspiration and motivation for the person using it, potentially gaining the symbolic meaning of directedness and purpose, and thus supporting subjective well-being. Participants in the study identified the potential of the product and its inferred design direction as follows: "It's about designing for mindfulness though giving control. It is a subtle everyday reminder" (DRP03). "It really involves the user in his own motivation routine" (DP02). "It reminds the user via cues of everyday objects. Giving cues to yourself in a ubiquitous way" (DRP01). "You are defining time, over and over again" (DP06).

Figure 5 Blank Wall Clock by Martí Guixé/Alessi (see online version for colours)

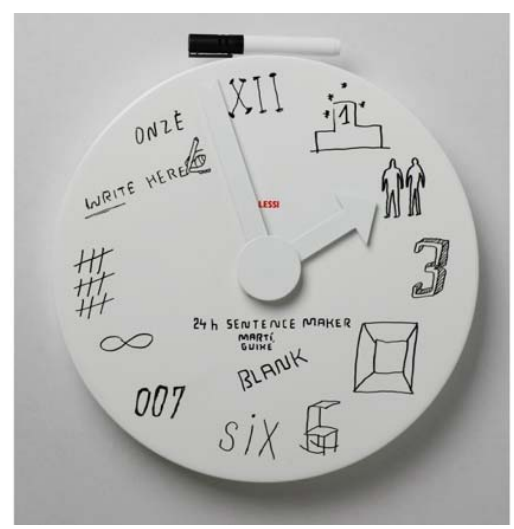

Note: Photo imagekontainer, reprinted with permission.

\subsubsection{Provide a sense of control}

The design direction 'provide a sense of control' can be put in practice by enabling people to manage personally significant goals or eliminate obstacles to their fulfilment. There is recognisable challenges people face when managing willpower: there must be a balance between the cognitive 'cool' system of thinking and the emotional and instinctive 'hot' system of doing. However, this balance is affected, and often undermined, by stress and the individual's ability to self-regulate (Metcalfe and Mischel, 1999). Research has shown that forming a pre-commitment improves chances of success in goal achievement, but that on their own (e.g., with self-imposed deadlines) people do not achieve optimal results (Ariely and Wertenbroch, 2002). In light of that, products can act as tangible commitment devices by supporting willpower, promoting good habits and lessening dilemmas. The value of delayed gratification has been recognised by previous studies (Doerr and Baumeister, 2010; Ryff, 1989), but it is not without its challenges; products that can facilitate it (Pohlmeyer and Desmet, 2017) can thereby potentially gain a symbolic meaning related to control, directedness and purpose, which in turn can support subjective well-being.

An example of a product that provides a sense of control by facilitating the elimination of obstacles in the pursuit of personally significant goals is the Kitchen Safe, designed by David Krippendorf and Ryan Tseng (kSafe) (Figure 6). The Kitchen Safe is a time-lock container that cannot be opened until the timer reaches zero. It allows people to have control over several situations, such as limiting unhealthy snacks, saving money by preventing mindless spending, unplugging from mobile devices or videogames, and 
cutting back on smoking. Study participants discussed the potential of this design direction through this product: "This is about designing something to teach people the value of patience and self-control" (DP04). "In the long term it helps build intrinsic motivation" (DRP01). "The strategy is to create a barrier. It creates symbolic meaning by motivating the person to stick to an important goal, it is done by eliminating whatever stands in the way of that goal. Eliminating the obstacles by creating a barrier. The designer can question: what are the obstacles, and how can I help eliminate them" (DRP03).

Figure 6 Kitchen Safe by kSafe (see online version for colours)
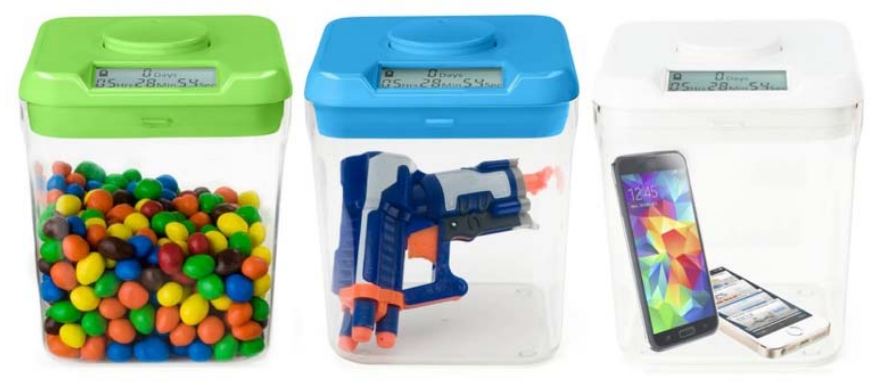

Note: Reprinted with permission.

\subsubsection{Keep track of progress}

The design direction 'keep track of progress' can be made concrete by providing visual feedback on progress towards personally significant goals. By feedback we mean an external response signalling progress towards a certain goal, with output, for example, at certain milestones or upon the completion of the goal. If a person aims to be more virtuous, such as by being more environmentally conscious, small steps can provide a sense of progress. Products that provide feedback on such steps can, by association, gain a symbolic meaning of directedness and purpose and thus support subjective well-being. Depending on a person's goals and aspirations, the measurement of progress can vary in difficulty; nevertheless, past research has pointed out that having a sense of purpose is essential to keep people motivated (e.g., Amabile and Kramer, 2011). The way people interpret feedback is also a crucial aspect to consider when designing. It is plausible to consider that people unconsciously undermine their progress towards a goal by giving themselves permission to relax after reaching a certain milestone, because they estimate having done outstanding work and fail to predict the actual amount of work still required. Feedback, therefore, is not just informative, but also has emotional consequences. This is relevant when designing for well-being, because when the information triggers positive emotions (for example, when the feedback is only perceived as positive) it can be a powerful motivating factor.

An example of a product that helps people keep track of progress on personally significant goals by providing measurable feedback is 999bottles by Artefact (see https://www.artefactgroup.com/work/999bottles). It is a reusable durable metal bottle with three numbered dials that count the number of plastic bottles that are 'saved'. It 
works with a mobile application that informs the person about the specific impact of different stages (e.g., ten bottles are the equivalent to the cost of the 999bottles, etc.). Together, the 999bottles and the application are designed to help people visualise the positive impact of their choices on the environment. Study participants pointed out the promising features of the 999bottles in regards to the design direction: "It encourages people to be more sustainable in a quantified way. It keeps track of behaviour" (DP04). "It makes the motivation tangible, that you can count it, or grasp it" (DP02). "It's about giving subtle rewards. What happens with personally meaningful goals is that they are not so visible to you, you can easily push them back. So you need something that brings them more to the foreground, and this bottle does that" (DRP03).

\subsection{Design directions for the symbolic meaning of environmental mastery}

The symbolic meaning of environmental mastery symbolises the ability to manage or create a suitable environment to accommodate personal needs and values. Two design directions resulted that aim to trigger this symbolic meaning:

1 support multi-sensorial communication

2 provide a context for meaningful interaction.

\subsubsection{Support multi-sensorial communication}

The design direction 'support multi-sensorial communication' can be put in practice by translating messages into a sensorial experience. Communication is an essential aspect of the creation of a suitable context for human flourishing. Face-to-face communication involves multiple modalities: verbal (words), para-verbal (tone) and non-verbal language, like touch, smell, and micro-expressions. From a design standpoint, this direction is interesting because a multi-sensorial approach can enrich the experiences people have with products (Schifferstein and Desmet, 2008; Schifferstein, 2011) and designers can manipulate all aspects of a product to influence the way it is experienced (Ludden and Schifferstein, 2009). From a user standpoint, research on the subject has indicated that product-mediated contact can effectively transmit affect, and is more powerful when it considers elements of human physicality such as touch and intentionality (Lenay, 2010; Smith and MacLean, 2007). Design interventions that consider these aspects can strengthen relationships and promote closeness (e.g., Visser et al., 2011).

This design direction suggests that by translating messages into sensorial experiences, a product can potentially gain symbolic meaning to a person by becoming a proxy of the intended receiver. People can more clearly convey emotions, more strongly react, and cultivate proximity even in a scenario of physical separation, than when using means of communication that rely on a simpler type of messaging. An illustrative example of a product that supports multi-sensorial communication by translating a message into a sensorial experience is the Elfoid P1 by Hiroshi Ishiguro Laboratory (Advanced Telecommunications Research Institute International) (Figure 7). This hybrid cell phone-robot concept is a simplified human figure that transmits voice and motion to convey human 'presence'. Supporting multi-sensorial ways of communicating represents an opportunity to enrich the message and the experience of receiving it by rendering it closer to a direct interaction and incorporating audio and/or kinaesthetic elements as a metaphor for intimate human behaviours. During the study, participants identified the 
potential of the design direction by referring to this product in the following way: "It's a platform for communication, it's an exchange of certain behaviours" (DRP03). "It's an imitation of reality, mimicking motion" (DRP01). "It's a way to communicate presence and physicality. It translates a physical action into something else" (DP04).

Figure 7 Elfoid $^{\mathrm{TM}}$ by Hiroshi Ishiguro Laboratories, Advanced Telecommunications Research Institute International/ATR (see online version for colours)

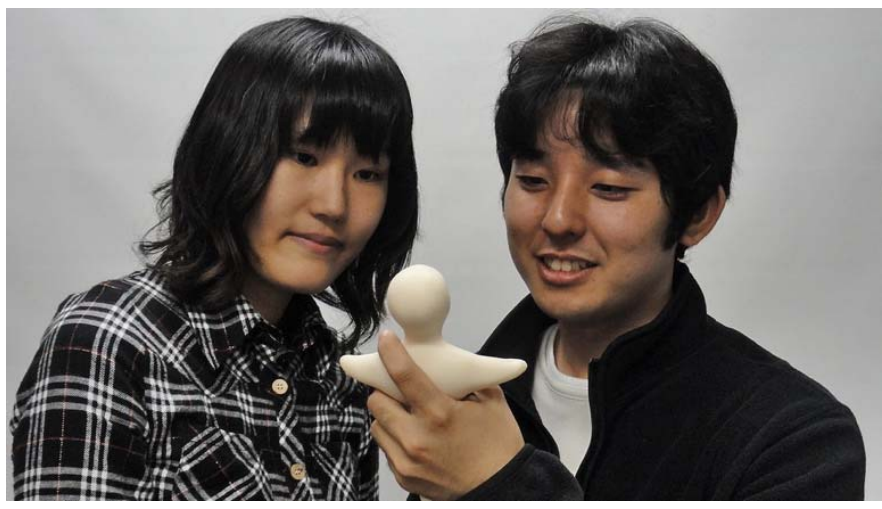

Note: Reprinted with permission.

\subsubsection{Provide a context for meaningful interaction}

The design direction 'provide a context for meaningful interaction' can be exercised by making use of the context or limitations as an advantage. This design direction is closely linked to the essence of environmental mastery, which is the ability to find, adapt or create a suitable context to thrive in Ryff (1989). Design is traditionally characterised as a discipline of solving problems, concerned particularly with bringing the user or product from an insufficient state towards a problem-free 'neutral' stage. While this is relevant in many contexts, such as in healthcare, we believe that going beyond this can have a great impact on the users and their context. Converse to a problem-driven approach, a possibility-driven design approach aims for an impact in the positive spectrum of experience (Desmet and Hassenzahl, 2012; Jimenez et al., 2014). Designing a context by looking at its limitations not as problems to be solved, but rather as opportunities to be explored can generate new and innovative interventions. Meaningful interactions can occur between different persons, between people and products, and between people and their environment, for instance. Designers can help create this value by enabling people to reframe the perceived limitations in their environment. A design intervention that helps people make the best of the context, and turns limitations into potential advantages, can potentially gain symbolic meaning and thus support well-being.

To illustrate this, imagine a child with cancer, who is confined to a hospital environment. The child's strength and disposition vary according to the stage of treatment, and in certain moments playing is not only desirable, but necessary for adequate physical and psychosocial development (Frost et al., 2012). However, play can be a challenge in this setting. An example of a product that makes use of physical limitations in the context of hospitalised children to provide meaningful interactions is KonneKt by designer Job Jansweijer (studio Elk). KonneKt is kit of shapes that can be 
attached to a window using suction cups (for individual play) or magnets (for group play) (Figure 8). It enables children to play games with their peers, using the very windows that physically divide and isolate them - usually seen as a limitation - as a playground. The given example is, of course, relevant for the specific context for which it was designed; however, designers can consider a similar strategy for different contexts. Participants in the study recognised the opportunities in this design direction by commenting on KonneKt's interesting elements: "These children have the motive for sharing and playing, and this product actually helps them under these challenging circumstances to do that, to actualize that value" (DRP03). "This product is enabling interaction between two users that cannot interact directly" (DP02).

Figure 8 KonneKt by Job Jansweijer (see online version for colours)

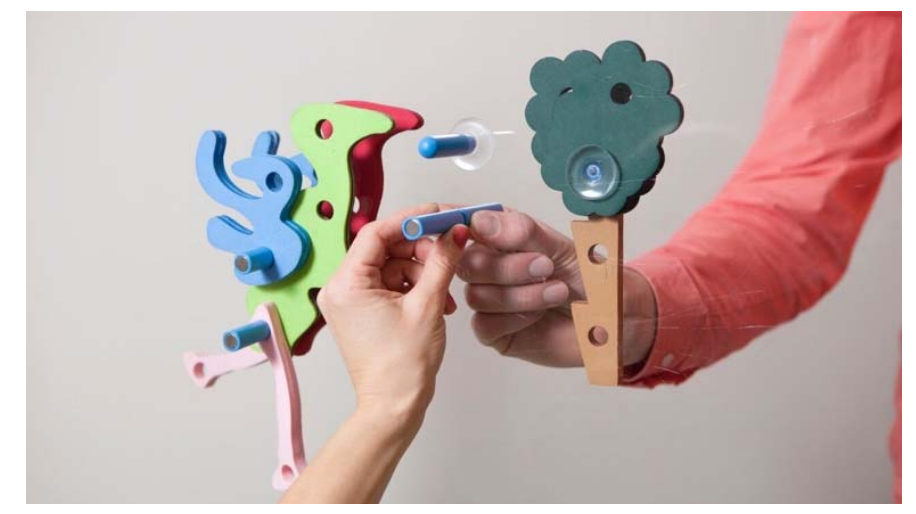

Note: Reprinted with permission.

\subsection{Design directions for the symbolic meaning of autonomy}

The symbolic meaning of autonomy signifies a sense of independence and self-reliance in both thought and action, and the ability to resist external pressures. Three of the resulting design directions aim to trigger this symbolic meaning:

1 destigmatise

2 design for mindfulness

3 redirect the user's attention.

\subsubsection{Destigmatise}

The design direction 'destigmatise' can be put to use by enhancing the aesthetic qualities of physically enabling products. Past research exploring the destigmatisation of assistive products through design (Vaes, 2014) has identified different levels of intervention: product-focused interventions (e.g., reshape a product meaning through advances in technology), people-focused interventions (e.g., endow the product user with extra abilities), and culture-focused interventions (e.g., campaigns or interventions that educate the public or change their views). We propose, in complement, that enhancing the aesthetic qualities of assistive products, not only through technology, but also through the normalisation of their features, can generate a strong meaning of empowerment to the 
person using them. Overcoming a recognisable aesthetic of physically enabling products, i.e., predominantly white using metallic and plastic materials, and presenting them as general consumer goods can reduce their stigmatising effects (Correia de Barros et al., 2011) and even produce positive emotions (Desmet and Dijkhuis, 2003). The symbolic connotation of the product to a person's sense of autonomy with an added feeling of 'normality' can generate value that contributes to their subjective well-being.

An example of a collection of products that aims to destigmatise by enhancing the aesthetic qualities of physically enabling products is the No Country for Old Men/Together Canes by designers Francesca Lanzavecchia and Hunn Wai (Lanzavecchia + Wai) (Figure 9). This collection of canes is described as 'walking aids for living, not just mobility', which suggests that in addition to providing physical support, the products were designed to accommodate modern living, such as using mobile devices. Study participants recognised the potential of the design direction by discussing this product in the following way: "This is really about making an object-based stigma into a beautiful intervention" (DP02). "It empowers you to feel like you are in control" (DRP01).

Figure 9 No Country for Old Men/Together Canes by Lanzavecchia + Wai (see online version for colours)

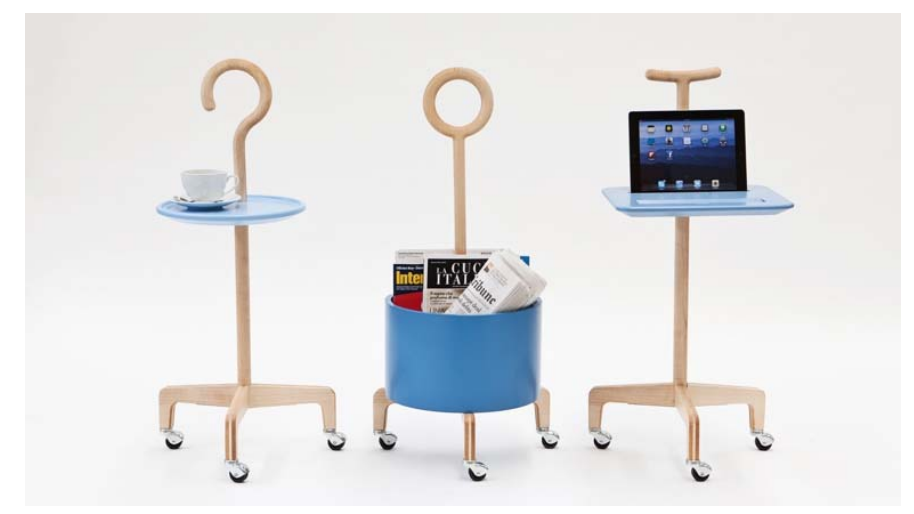

Note: Reprinted with permission.

\subsubsection{Design for mindfulness}

The design direction 'design for mindfulness' can be applied by slowing down processes or disclosing mechanisms behind products to promote mindful living. Fuad-Luke (2010) introduced a 'slow design' approach to improve and extend person-product relationships, through which the author proposed to explore greater awareness and sensibility regarding design, production, and consumption. In complement to this idea, the design direction proposes that, at a product level, designers can explore the mechanisms and processes that enable products to function, and expose or modify them to allow people's agency and intentionality to play a role in product use.

An example of a product that was designed for mindful use by disclosing its mechanism is the Standard Lamp, a part of the Standard Collection by designers Calen Knauf and Conrad Brown (Knauf and Brown) (Figure 10). The lamp does not have an 'on-off' switch, so the person using it has to choose between two kinds of fixtures and place it in a copper tower to complete an electric circuit. In this product, the person's 
agency and autonomy are evidenced because the processes that make the lamp function are not automatic, and the person has to intentionally perform them. The result is that the person builds a thoughtful relationship with the product, actively making decisions that usually would not be necessary, which fosters mindful and attuned living. This relates to autonomy because it contributes to a sense of self-reliance in the user by enabling them to understand the process and intervene in any part of it. Previous research has recognised the slowing down or disclosing of processes behind products as a way to ritualise product use, which results in added value and an improved experience (Fuad-Luke, 2010). In turn, this approach contributes to delaying gratification, which is a valuable aspect of well-being (Doerr and Baumeister, 2010; Ryff, 1989). Participants from the study identified the potential of this design strategy through the discussion of the Standard Lamp's features and effects: "It's about designing something to help people reflect on everyday given things, objects, actions; to challenge people on actions that they would otherwise perform without thinking, by increasing effort" (DP04). "It's about challenging assumptions, how you think of your mindset, your attitude, so it triggers something" (DRP03).

Figure 10 The Standard Lamp by Knauf and Brown (see online version for colours)

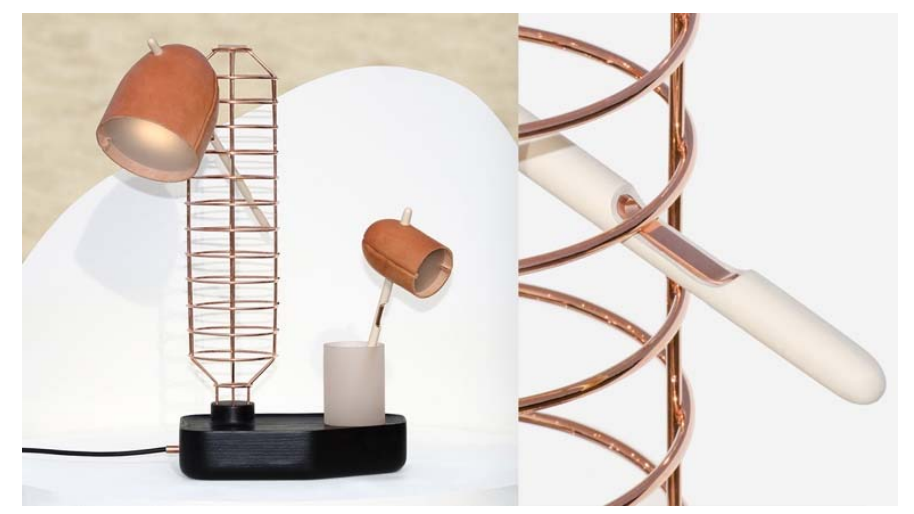

Note: Reprinted with permission.

\subsubsection{Redirect the user's attention}

The design direction 'redirect the user's attention' can be put into practice by designing an intervention that requires attention from the person, thereby distracting from negative situations. Instead of solving a problem, this type of design strategy focuses on an opportunity that has great potential to improve people's lives, such as by fulfilling a need for relatedness (Desmet and Hassenzahl, 2012). This 'caretaking' role the person takes on with the product can temporarily decrease the attention they might be bestowing on negative situations, and promote feelings of competence and control, and thus potentially provide the product with a symbolic meaning related to autonomy. An (extreme) anecdote to illustrate this is a child with cancer, afflicted by a debilitating health problem and limited in most normal child-like activities. A design intervention that actively asks for the child's attention can potentially distract from the illness and restore a sense of autonomy by supporting the ability to be the caretaker as opposed to the one being taken care of. An example of a product that does this is Liv, developed by a team of design 
students (Floris Plink, Hylke Visser, Josette Kuipéri, Leonard Moonen, Lotte Salomé, Saskia Mosterman, and Seungmin Lee) mentored by Marco Rozendaal, Aadjan van der Helm and Chris Kievid (minor course Interactive Environments, Faculty of Industrial Design Engineering, TU Delft). Liv is an interactive creature that requires movement and social attention (Figure 11). Specifically, it emits sound and colour signals that indicate that it wants to be played with or wants social contact with other Livs. Liv aims to encourage more active and social behaviour from hospitalised children, which is expected to improve their emotional well-being. By providing entertainment and stimulation, robots and other interactive devices can effectively improve the objective and subjective well-being of healthcare users and decrease isolation (Robinson et al., 2013). Study participants discussed this product example and identified the potential of the inferred design direction: “It's about relatedness. It's like a Tamagotchi. It's about the need to care for others and to be cared for" (DP02). "The object asks for attention. By demanding attention, you get distracted. It reminds the user in visual cues. It provides pretext for interaction" (DRP01).

Figure 11 Liv by TU Delft/Interactive Environments (see online version for colours)

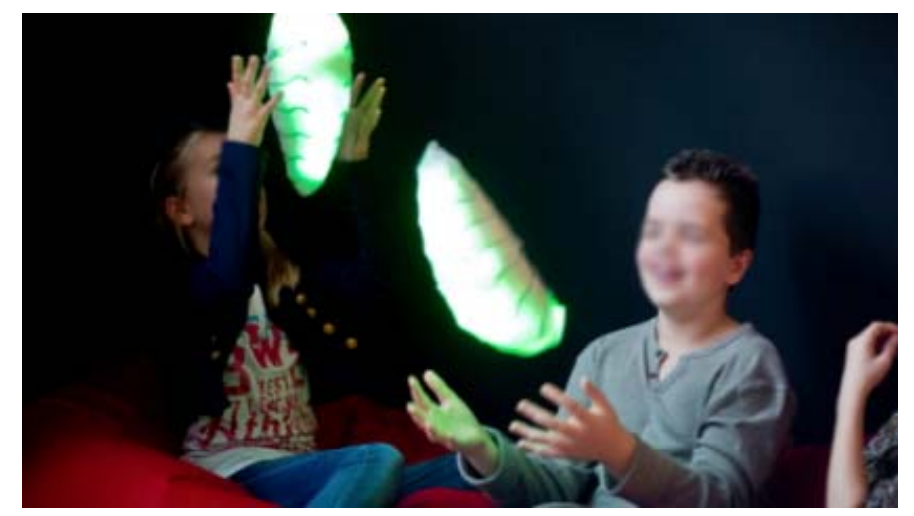

Note: Reprinted with permission.

\subsection{Design directions for the symbolic meaning of self-acceptance}

The symbolic meaning of self-acceptance signifies the acceptance of positive and negative aspects of oneself, self-compassion and a positive self-image. Two of the resulting design directions aim to trigger this symbolic meaning:

1 allow shared transformation

2 allow self-expression.

\subsubsection{Allow shared transformation}

The design direction 'allow shared transformation' can be put in practice by providing tools for people's input at an aesthetic and/or functional level. This design direction suggests that a product that invites people to invest time and effort in it can gain symbolic meaning. The transformation of the object can lead, to some extent, to the transformation of the person as well: someone who invests time and effort to modify something is also 
affected by it, such as by releasing their creativity. In addition, an object that is transformed by a person retains marks of intentionality as a signature. Accepting the result of such transformation can help people have a positive view on the self ("I made this and it is beautiful/unique"). One way this design direction could be implemented is by facilitating temporary or permanent transformations of an intentionally incomplete product. Previous research supports the idea that unfinished products invite exploration, resulting in enhanced product attachment (Borjesson, 2009; Mugge et al., 2009). A longer and more meaningful relationship with a product can, in turn, offer clearer signals of self-image. Of the 16 proposed design directions, this is the one that most literally activates people to immerse their own narratives in a product and its features.

An example of a product that allows shared transformation by giving room for people's input at an aesthetic and functional level is the Meaning of Time by designer Bomi Kim (Figure 12). It is a clock mechanism without hands, which invites a person to insert a tangible element to complete the object, involving him/her in the aesthetic and functional outcome of the object. Participants in the study acknowledged the possibilities of this design strategy by discussing the product example in the following way: "The user has significant influence on how the object ends up looking or behaving. The product wouldn't function without input. It's Do It Yourself" (DRP03). "Unfinished product enables or supports your own creation. It enables expression. It has the goal of motivating a user to be more creative" (DRP01).

Figure 12 The Meaning of Time by Bomi Kim (see online version for colours)

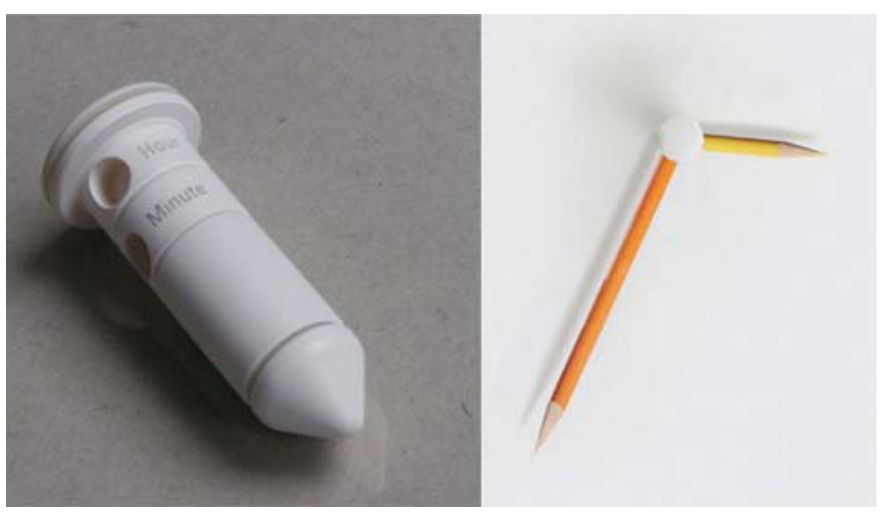

Note: Reprinted with permission.

\subsubsection{Allow self-expression}

The design direction 'allow self-expression' can be put in use by providing a tangible platform to wear, share or display personally significant ideas. Products have been recognised as important vessels of construction and communication of personal identity (e.g., Belk, 1988; Ledgerwood et al., 2007; Wicklund and Gollwitzer, 1981), facilitating the creation of coherent self-narratives (Ahuvia, 2005). A product that can display and communicate changing ideas is able to adapt to the evolution of the self and remain relevant. Furthermore, the dynamic communication of those ideas, for example in a wearable and/or sharable platform, has the potential to strengthen the product's relevance as a means for self-expression. A product that facilitates the expression of personally 
significant ideas can potentially gain a meaning related to self-acceptance, thereby contributing to subjective well-being. Self-expression is an important aspect of individuality, because its result can be perceived as an extension of the self. When a person expresses himself or herself, the result of that expression teaches them about his or her abilities, which contributes to self-knowledge and can help with the acceptance of strengths and shortcomings. Furthermore, products can have a strong influence on our own sense of who we are (Ahuvia, 2005).

An example of a product that allows self-expression through a wearable and shareable platform is tshirtOS by CuteCircuit. This product is a programmable t-shirt that, among other features, can play songs and display social media information and both moving and static pictures (see http://cutecircuit.com/tshirtos). It is controlled by a mobile application, and includes hardware such as a built-in camera, a microphone and speakers. Participants in the study discussed the potential of the inferred design strategy of tshirtOS in the following way: "It's a wearable platform to express yourself" (DRP01). "It's a product for self-expression that can work as an ice-breaker or conversation starter" (DP04).

\section{General discussion}

Previous research has postulated that attributing symbolic value to products is a way to support subjective well-being (Pohlmeyer, 2012). This type of value does not come from ownership, but from what products enable and represent to people (Pohlmeyer and Desmet, 2017): for example, the significance of a product can relate to shared values and the contribution to something bigger than the self (Donnelly et al., 2016; Escobar-Tello, 2016), to meaningful life events (Goodman et al., 2016), and to happy experiences (Yang et al., 2017) and thus the product contributes to subjective well-being. In our research, we have taken on the challenge of developing design directions that aim to inspire designs that are likely candidates for symbolic meaning attribution.

Products can gain symbolic meaning and become symbolic representations if people associate them with specific experiences, memories or ideas. An initial exploration of that potential has identified well-being related symbolic meanings in products (Casais et al., 2016). Nevertheless, an operationalisation of that knowledge can make it more useful as a direct source of inspiration in design processes, because symbolic meaning can be somewhat abstract and designers can benefit from having clear and specific directions for how to achieve this in practice. In this paper we have reported a study that explored and analysed existing products, and, based on the perspectives of designers and design researchers, inferred meaning-driven design directions. We focus on the potential universality of design for well-being, trying to produce general principles that provide a systematic way to work, and from there address individual concerns of specific users and contexts. The study resulted in 16 design directions that aim to trigger six symbolic meanings. Two design directions support 'positive relations with others': 'support meaningful affiliations' and 'embody characteristics of a group'. Four of the design directions support 'personal growth': 'support active personal development', 'embody personal growth', 'support acceptance and growth from past experiences', and 'enhance memories'. Three design directions relate to 'purpose in life': 'encourage positive change', 'provide a sense of control', and 'keep track of progress. Two design directions concern 'environmental mastery': 'support multi-sensorial communication' and 'provide 
a context for meaningful interaction'. Three design directions support 'autonomy': 'destigmatise', 'design for mindfulness', and 'redirect the user's attention'. Finally, two design directions relate to 'self-acceptance': 'allow shared transformation' and 'allow self-expression' (for an overview and further details see Table 4).

\subsection{Reflection on the findings}

The current paper contributes to positive design with an initial exploration of what design directions can support designers in attempts to design for six well-being related symbolic meanings. Symbolic meaning is constructed by unique personal narratives. As such, a common denominator in the presented design directions is the agency of the owner in the construction of meaning. Since meaning is attributed by the individual, it may differ between people and may be unexpected or unintended by the designer. We therefore consider our study results to be directions to design with symbolic meaning (for symbolic meaning attribution), rather than designing for symbolic meaning, i.e., designing prescriptively for a specific symbolic meaning. In doing so, we recognise the person's agency in the construction of the product's meaning. This co-construction of meaning (between the designer and the user) can be exemplified with a product that is intentionally designed to be incomplete, with the aim of having the owner finish it, therefore allowing a personal narrative to be inscribed and the corresponding meaning to be created. Rather than designing meaning, the designer develops products that are likely candidates for symbolic meaning attribution by asking for the person's attention, care, functional and aesthetic input. Eventually, the person's narratives are the key elements that bring these design interventions to life, build their symbolic meanings, and make them support well-being. While it has not been tested, products that invite their owners to ascribe meaning to them seek to overcome or minimise the difficulties of design with symbolic meaning, and its person- and context-dependency.

Even though each proposed design direction emerges from one symbolic meaning and is presented in that category, it is possible to recognise that several directions fit multiple symbolic meanings.

\subsection{Limitations and opportunities for future research}

In the current study, we sought to infer what strategies the actual designers of the used product examples employed when developing the selected product examples, referring back to a framework of symbolic meaning. Future research can interview the designers of the selected products about their actual intentions, which might disclose other or additional possibilities (see also the work of Da Silva et al., 2015). Furthermore, we have yet to test how usable these design directions are in a design context. Presenting design directions to design professionals is valuable both in practice (for novice and expert designers, see Daalhuizen and Badke-Schaub, 2011) and in education (Lim et al., 2011). Design directions can make complex processes easier, such as switching between design solutions (Daalhuizen and Badke-Schaub, 2011), and sensitise designers about a certain topic or theory. Further research can be conducted to apply our findings and extend the existing knowledge about the role of design in well-being. Specifically, ways to effectively communicate the results of this research to designers can be explored. A quick exercise in a design class with about 30 novice designers indicated that the design directions were clear and not difficult to use; however, future research can look at how 
novice and expert designers perceive and use the design directions to determine whether these would need to be presented differently.

Our aim is that the products developed with the design directions can help people become more aspirational, anticipate experiences and then experience them, and recall and share them with others. In such a way, the design direction can support subjective well-being, which could then be assessed. The assumptions that guided the interpretation of results about the effect of the design directions on end-users are based on the informed opinions and predictions of design experts, supported by existing literature. To complement and strengthen our results, future research can consider observing these effects in real situations. On a more general level, future research on positive design could focus on tools for assessing the effect of the designed interventions on people's well-being.

A potential pitfall of this general strategy of using symbolic meaning in products is that the associations people make may appear positive in the short term (for example, associating personally significant goals with certain products), but conducive to ill-being in the long term: such is the case with conspicuous consumption, in which the meanings associated with products reflect an aspirational reality (such as being richer or better) and may remind the person of their lack of accomplishment or the 'fake' reality they attempt to portray through material possessions (Friese, 2000). In order to ensure that designers consider the person- and context-dependency of meaning, and its potential positive and negative effects, thought-provoking questions can be added to the design directions, with the purpose of making the designers reflect more deeply on the specific user group and context for which they are designing.

In this study we used durable consumer goods, such as household items, as a reference to construct the design directions. We focused on consumer durables because people often interact with these products. Nevertheless, future research can explore other typologies of products or domains of intervention, such as spaces or buildings. Other applications, such as intangible goods or services, may also benefit from the design for well-being directions, as these can provide pathways for designers to develop better experiences for different users, for example in online environments, in mobile applications and in a retail context.

In our study, we enabled the participants to familiarise themselves with the 50 product designs for three days before the study by sending them cards with the designs. This procedure allowed us to use a large pool of stimuli, that is, more designs than we could have included if we would have confronted the participants with the designs at the start of the session. This procedure may have influenced the results; participants may have had other ideas and responses in a first encounter with the designs. Future research can consider such first impressions. In addition, due to practical reasons, we had to rely on pictures of the products, which is a limited representation of the designs. Ideally, future studies will include real products rather than, or in addition to, stimuli cards with pictures and descriptions. The instruction-based strategy that was used in the study to produce design directions might also have had consequences such as fixation on certain solutions or being too leading. Follow-up studies can be conducted to minimise this effect.

Another opportunity for future research concerns the consequences for sustainable behaviour of using products or living and operating in environments that support wellbeing. Based on previous research (e.g., Trudel et al., 2016) products with such value are expected to be used and disposed of in a more sustainable way, and such environments 
can be expected to stimulate and encourage sustainable ways of living (Escobar-Tello and Bhamra, 2013; Escobar-Tello, 2016). Future research can explore further the consequences for sustainable behaviour of products and environments that are designed with a focus on well-being through symbolic meaning.

\section{Acknowledgements}

This research was supported by the FCT - Fundação para a Ciência e Tecnologia (Foundation for Science and Technology), an organization within the Ministry of Education and Science of Portugal (grant number SFRH/BD/77337/2011). We would like to acknowledge all the willing participants for their availability and contributions.

\section{References}

Abalada, A. (2014) 'Design for emotional well-being: a tactile and a material investigation', in Lim, Y-K. et al. (Eds.): Proceedings of DRS 2014: Design's Big Debates, Umeå Institute of Design, Umeå University, Umeå, Sweden.

Amabile, T.M. and Kramer, S.J. (2001) 'The power of small wins', Harvard Business Review, May 2011, Vol. 89, No. 5, pp.4-12.

Ariely, D. and Wertenbroch, K. (2002) 'Procrastination, deadlines, and performance: self-control by precommitment', Psychological Science, Vol. 13, No. 3, pp.219-224.

Baumeister, R.F. and Leary, M.R. (1995) 'The need to belong: desire for interpersonal attachments as fundamental human motivation', Psychological Bulletin, Vol. 117, No. 3, pp.497-529.

Belk, R. (1988) 'Possessions and the extended self', Journal of Consumer Research, Vol. 15, No. 2, pp.139-168.

Bernecker, K., Herrmann, M., Brandstätter, V. and Job, V. (2017) 'Implicit theories about willpower predict subjective well-being', Journal of Personality, Vol. 85, No. 2, pp.136-150.

Bohlmeijer, E. (2007) Reminiscence and Depression in Later Life, PhD thesis, Vrije Universiteit, Amsterdam, The Netherlands.

Boniwell, I. (2012) Positive Psychology in a Nutshell: The Science of Happiness, Open University Press, Berkshire.

Borjesson, K. (2009) 'Affective sustainability. Is this what timelessness really means?', in Durling, D. et al. (Eds.): Undisciplined! Proceedings of the Design Research Society Conference 2008, Sheffield Hallam University, Sheffield, England, pp.1-16.

Bryan, J.F. and Locke, E.A. (1967) 'Goal setting as a means of increasing motivation', Applied Psychology, Vol. 51, No. 3, pp.274-277.

Burt, C.D.B. (1994) 'Prospective and retrospective account-making in diary entries: a model of anxiety reduction and avoidance', Anxiety, Stress and Coping: An International Journal, Vol. 6, No. 4, pp.327-340.

Casais, M., Mugge, R. and Desmet, P.M.A. (2016) 'Meaningful things. Exploring the symbolic meaning of the material environment and its impact on happiness', Videography, presented at ACR 2016 - Association of Consumer Research Conference, Wanderlust, Berlin, Germany, 27-39 October 2016 [online] http://www.vimeo.com/179011005.

Chapman, J. (2005) Emotionally Durable Design: Objects, Experiences and Empathy, Earthscan, London.

Chiang, K-J., Chu, H., Chang, H-J., Chung, M-H., Chen, C-H., Chiou, H-Y. and Chou, K-R. (2010) 'The effects of reminiscence therapy on psychological well-being, depression, and loneliness among the institutionalized aged', International Journal of Geriatric Psychiatry, Vol. 25, No. 4, pp.380-388. 
Correia de Barros, A., Duarte, C. and Cruz, J.B. (2011) 'The influence of context on product judgement: presenting assistive products as consumer goods', International Journal of Design, Vol. 5, No. 3, pp.99-112.

Corrigan-Doyle, E., Escobar-Tello, C. and Ying Lo, K.P. (2016) 'Exploring design for happiness in the home and implications for future domestic living', in Lloyd, P. and Bohemia, E. (Eds.): Proceedings of DRS2016: Design + Research + Society - Future-Focused Thinking, Vol. 4, pp.1529-1552, Design Research Society, Brighton.

Csikszentmihalyi, M. and Rochberg-Halton, E. (1981) The Meaning of Things: Domestic Symbols and the Self, Cambridge University Press, Cambridge.

Da Silva, O., Crilly, N. and Hekkert, P. (2015) 'How people's appreciation of products is affected by their knowledge of the designers' intentions', International Journal of Design, Vol. 9, No. 2, pp.21-33.

Daalhuizen, J.J. and Badke-Schaub, P.G. (2011) 'The use of methods by advanced beginner and expert industrial designers in non-routine situations: a quasi-experiment', International Journal of Product Development, Vol. 15, Nos. 1-3, pp.54-70.

Desmet, P.M.A. (2011) 'Design for happiness: four ingredients for designing meaningful activities', in Chen, L-L. et al. (Eds.): Proceedings of the 4th World Conference on Design Research, Delft University of Technology, Delft, pp.1-11.

Desmet, P.M.A. (2012) 'Faces of product pleasure: 25 positive emotions in human-product interactions', International Journal of Design, Vol. 6, No. 2, pp.1-29.

Desmet, P.M.A. and Dijkhuis, E. (2003) 'A wheelchair can be fun: a case of emotion-driven design', in Proceedings of the International Conference on Designing Pleasurable Products and Interfaces, Pittsburgh, ACM, New York, pp.22-27.

Desmet, P.M.A. and Hassenzahl, M. (2012) 'Towards happiness: possibility-driven design', Human-Computer Interaction: The Agency Perspective, pp.3-27, Springer, Berlin.

Desmet, P.M.A. and Pohlmeyer, A.E. (2013) 'Positive design: an introduction to design for subjective well-being', International Journal of Design, Vol. 7, No. 3, pp.5-19.

Desmet, P.M.A., Fokkinga, S.F., Ozkaramanli, D. and Yoon, J. (2016) 'Emotion-driven product design', in Meiselman, H.L. (Ed.): Emotion Measurement, pp.405-426, Elsevier, Amsterdam.

Dittmar, H. (1991) 'Meanings of material possessions as reflections of identity: gender and social-material position in society', Journal of Social Behavior and Personality, Vol. 6, No. 6, pp.165-186.

Doerr, C.E. and Baumeister, R.F. (2010) 'Self-regulatory strength and psychological adjustment', in Maddux, J.E. and Tangney, J.P. (Eds.): Social Psychological Foundations of Clinical Psychology, pp.71-83, The Guildford Press, New York.

Donnelly, G.E., Lamberton, C., Walker Reczek, R. and Norton, M.I. (2016) 'Social recycling transforms unwanted goods into happiness', Journal of the Association for Consumer Research, Vol. 2, No. 1, pp.48-63.

Eid, M. and Diener, E. (2004) 'Global judgments of subjective well-being: situational variability and long-term stability', Social Indicators Research, Vol. 65, No. 3, pp.245-277.

Escobar-Tello, C. (2016) 'A design framework to build sustainable societies: using happiness as leverage', The Design Journal, Vol. 19, No. 1, pp.93-115.

Escobar-Tello, C. and Bhamra, T. (2013) 'Happiness as a harmonising path for bringing higher education towards sustainability', Environment, Development and Sustainability, Vol. 15, No. 1, pp.177-197.

Fokkinga, S.F. and Desmet, P.M.A. (2013) 'Ten ways to design for disgust, sadness, and other enjoyments: a design approach to enrich product experiences with negative emotions', International Journal of Design, Vol. 7, No. 1, pp.19-36.

Fournier, S. (1991) 'Meaning-based framework for the study of consumer-object relations', in Holman, R. and Solomon, M.R. (Eds.): Advances in Consumer Research, Vol. 18, pp.736-742, Provo, Association for Consumer Research. 
Friedmann, R. and Lessig, V.P. (1986) 'A framework of psychological meaning of products', in Lutz, R.J. (Ed.): Advances in Consumer Research, Vol. 13, pp.338-342, Association for Consumer Research, Provo.

Friese, S. (2000) Self-Concept and Identity in a Consumer Society: Aspects of Symbolic Product Meaning, Tectum Verlag, Marburg.

Frisina, P.G., Borod, J.C. and Lepore, S.J. (2004) 'A meta-analysis of the effects of written emotional disclosure on the health outcomes of clinical populations', The Journal of Nervous and Mental Disease, Vol. 192, No. 9, pp.629-634.

Frost, J.L., Wortham, S.C. and Reifel, S. (2012) Play and Child Development, Pearson, Boston.

Fuad-Luke, A. (2010) 'Adjusting our metabolism: Slowness and nourishing rituals of delay in anticipation of a post-consumer age', in Cooper, T. (Ed.): Longer Lasting Products, pp.133-155, Gower Publishing, Surry.

Gioia, D.A., Corley, K.G. and Hamilton, A.L. (2012) 'Seeking qualitative rigor in inductive research: notes on the Gioia methodology', Organizational Research Methods, Vol. 16, No. 1, pp.15-31.

Goodman, J.K., Malkoc, S.A. and Stephenson, B.L. (2016) 'Celebrate or commemorate? A material purchase advantage when honoring special life events', Journal of the Association for Consumer Research, Vol. 1, No. 4. pp.497-508.

Hekkert, P. and Cila, N. (2015) 'Handle with care! Why and how designers make use of product metaphors', Design Studies, September, Vol. 40, pp.196-217.

Huisman, G., van Hout, M., van Dijk, E.M.A.G., van der Geest, T. and Heylen, D.K.J. (2013) 'LEMtool - measuring emotions in visual interfaces', in Proceedings of the SIGCHI Conference on Human Factors in Computing Systems - CHI 2013, AMC, New York, pp.351-360.

Isaacs, E., Konrad, A., Walendowski, A., Lennig, T., Hollis, V. and Whittaker, S. (2013) 'Echoes from the past: how technology mediated reflection improves well-being', in Proceedings of the SIGCHI Conference on Human Factors in Computing Systems - CHI'13, ACM, New York, pp.1071-1080.

Jimenez, S., Pohlmeyer, A.E., Desmet, P.M.A. and Huzen, G. (2014) 'Learning from the positive: a structured approach to possibility-driven design', in Salamanca, J. et al. (Eds.): Proceedings of the Colors of Care: The 9th International Conference on Design \& Emotion, Ediciones Uniandes, Bogotá, pp.607-615.

Kleine, R.E. and Kernan, J.B. (1988) 'Measuring the meaning of consumption objects: an empirical investigation', in Houston, M.J. (Ed.) Advances in Consumer Research, Vol. 15, pp.498-504, Association for Consumer Research, Provo.

Lacey, E. (2009) 'Contemporary ceramic design for meaningful interaction and emotional durability: a case study’, International Journal of Design, Vol. 3, No. 2, pp.87-92.

Ledgerwood, A., Liviatan, I. and Carnevale, P.J. (2007) 'Group identity completion and the symbolic value of property', Psychological Science, Vol. 18, No. 10, pp.873-878.

Lenay, C. (2010) 'It's so touching': emotional value in distal contact', International Journal of Design, Vol. 4, No. 2, pp.15-25.

Leung, A., Kier, C., Fung. T., Fung, L. and Sproule, R. (2011) 'Searching for happiness: the importance of social capital', Journal of Happiness Studies, Vol. 12, No. 3, pp.443-462.

Lim, Y., Lee, S. and Kim, D. (2011) 'Interactivity attributes for expression-oriented interaction design', International Journal of Design, Vol. 5, No. 3, pp.113-128.

Lin, R.T. (2007) 'Transforming Taiwan aboriginal cultural features into modern product design: a case study of a cross-cultural product design model', International Journal of Design, Vol. 1, No. 2, pp.45-53.

Love, L.L. and Sheldon, P.S. (1998) 'Souvenirs: messengers of meaning', Advances in Consumer Research, January, Vol. 25, pp.170-175.

Ludden, G.D.S. and Schifferstein, H.N.J. (2009) 'Should Mary smell like biscuit? Investigating scents in product design', International Journal of Design, Vol. 3, No. 3, pp.1-12. 
Lyubomirsky, S. (2007) The How of Happiness, The Penguin Press, New York.

Lyubomirsky, S. and Kurtz, J. (2008) Positively Happy. Routes to Sustainable Happiness, CreateSpace, London.

McCracken, G. (1986) 'Culture and consumption: a theoretical account of the structure and movement of the cultural meaning of consumer goods', Journal of Consumer Research, Vol. 13, No. 1, pp.71-84.

Mehta, R. and Belk, R.W. (1991) 'Artifacts, identity, and transition: favorite possessions of Indians and Indian immigrants to the United States', Journal of Consumer Research, Vol. 17, No. 4, pp.398-411.

Metcalfe, J. and Mischel, W. (1999) 'A hot/cool-system analysis of delay of gratification: dynamics of willpower', Psychological Review, Vol. 106, No. 1, pp.3-19.

Mols, I., van den Hoeven, E. and Eggen, B. (2017) 'Balance, Cogito and Dott: exploring media modalities for everyday-life reflection', in Proceedings of the Eleventh International Conference on Tangible, Embedded, and Embodied Interaction - TEI'17, ACM, New York, pp.427-433.

Mugge, R., Schoormans, J.P.L. and Schifferstein, H.N.J. (2008) 'Product attachment: design strategies to stimulate the emotional bonding to products', in Hendrik N.J. Schifferstein et al. (Eds.): Product Experience, pp.425-440, Elsevier, Amsterdam.

Mugge, R., Schoormans, J.P.L. and Schifferstein, H.N.J. (2009) 'Emotional bonding with personalized products', Journal of Engineering Design, Vol. 20, No. 5, pp.467-476.

Ozkaramanli, D. and Desmet, P.M.A. (2012) 'I knew I shouldn't, yet I did it again! Emotion-driven design as a means to subjective well-being', International Journal of Design, Vol. 6, No. 1, pp.27-39.

Petermans, A. and Pohlmeyer, A.E. (2014) 'Design for subjective well-being in interior architecture', in Proceedings of the 6th Annual Architectural Research Symposium: Designing and Planning the Built Environment for Human Well-Being, Oulu School of Architecture (OSA), Finland, pp.206-218.

Pohlmeyer, A.E. (2012) 'Design for happiness', Interfaces, Autum, Vol. 92, pp.8-11.

Pohlmeyer, A.E. and Desmet, P.M.A. (2017) 'From good to the greater good', in Chapman, J. (Ed.): Routledge Book of Sustainable Product Design, pp.469-486, London, Taylor \& Francis.

Richins, M.L. (1994). 'Valuing things: the public and private meanings of possessions', Journal of Consumer Research, Vol. 21, No. 3, pp.504-521.

Robinson, H., MacDonald, B., Kerse, N. and Broadbent, E. (2013) 'The psychosocial effects of a companion robot: a randomized controlled trial', Journal of the American Medical Directors Association, Vol. 14, No. 9, pp.661-667.

Ruitenberg, H.P. and Desmet, P.M.A. (2012) 'Design thinking in positive psychology. The development of a product-service combination that stimulates happiness-enhancing activities', in Brassett, J. et al. (Eds.): Proceedings of the 8th International Design and Emotion Conference, Central Saint Martin College of Art and Design, London, England, pp.1-10.

Ryff, C.D. (1989) 'Beyond Ponce de Leon: new directions in quest of successful ageing', International Journal of Behavioral Development, Vol. 12, No. 1, pp.35-55.

Ryff, C.D. (1995) 'Psychological well-being in adult life', Current Directions in Psychological Science, Vol. 4, No. 4, pp.99-104.

Sääksjärvi, M., Hellén, K. and Desmet, P. (2015) 'The effects of the experience recommendation on short-and long-term happiness', Marketing Letters, Vol. 27, No. 4, pp.1-12.

Schifferstein, H.N.J. (2011) 'Multi sensory design', in Hooper, C.J. et al. (Eds.): Proceedings of the DESIRE'11 Conference: Creativity and Innovation in Design, ACM, New York, pp.361-362.

Schifferstein, H.N.J. and Desmet, P.M.A. (2008) 'Tools facilitating multi-sensory product design', The Design Journal, Vol. 11, No. 2, pp.137-158. 
Sheldon, K.M. and Kasser, T. (2001) 'Getting older, getting better? Personal strivings and psychological maturity across the life span', Developmental Psychology, Vol. 37, No. 4, pp.491-501.

Smith, J. and MacLean, K. (2007) 'Communicating emotion through a haptic link: design space and methodology', International Journal of Human-Computer Studies, Vol. 65, No. 4, pp.376-387.

Snyder, C.R. and Lopez, S.J. (2002) The Oxford Handbook of Positive Psychology, Oxford University Press, New York.

Sosin, D. (1983) 'The diary as transitional object in female adolescent development', Adolescent Psychiatry, January, Vol. 11, pp.92-103.

Trudel, R., Argo, J.J. and Meng, M.D. (2016) 'The recycled self: consumers' disposal decisions of identity-linked products', Journal of Consumer Research, Vol. 43, No. 2, pp.246-264.

Vaes, K. (2014) Product Stigmaticity: Understanding Measuring and Managing Product-Related Stigma, PhD thesis, Delft University of Technology, Delft, The Netherlands.

Van Krieken, B., Desmet, P.M.A., Aliakseyeu, D. and Mason, J. (2012) 'A sneaky kettle: emotionally durable design explored in practice', in Brassett, J. et al. (Eds.): Proceedings of the 8th International Design and Emotion Conference, Central Saint Martin College of Art and Design, London, England.

van Nes, N. and Cramer, J. (2005) 'Influencing product lifetime through product design', Business Strategy and the Environment, Vol. 14, No. 5, pp.286-299.

Veenhoven, R. (2012) 'Happiness, also known as 'life satisfaction' and 'subjective well-being', in Land, K.C. et al. (Eds.): Handbook of Social Indicators and Quality of Life Research, pp.63-77, Springer Publishers, Dordrecht.

Visser, T., Vastenburg, M.H. and Keyson, D.V. (2011) 'Designing to support social connectedness: the case of SnowGlobe', International Journal of Design, Vol. 5, No. 3, pp.129-142.

Wallendorf, M. and Arnould, E.J. (1988) “My favorite things': a cross-cultural inquiry into object attachment, possessiveness, and social linkage', Journal of Consumer Research, Vol. 14, No. 4, pp.531-547.

Wicklund, R.A. and Gollwitzer P.M. (1981) 'Symbolic self-completion, attempted influence, and self-deprecation', Basic and Applied Social Psychology, Vol. 2, No. 2, pp.89-114.

Widman, D.R., Corcoran, K.E. and Nagy, R.E. (2009) 'Belonging to the same religion enhances the opinion of others' kindness and morality', Journal of Social, Evolutionary, and Cultural Psychology, Vol. 3, No. 4, pp.281-289.

Wilson, T.D. and Gilbert, D.T. (2008) 'Explaining away: a model of affective adaptation', Perspectives on Psychological Science, Vol. 3, No. 5, pp.370-386.

Yang, X., Aurisicchio, M., Mackrill, J. and Baxter, W. (2017) 'On the products and experiences that make us happy', in Proceedings of the 21st International Conference on Engineering Design - ICED 17, [online] http://iyangxi.me/img/portfolio/ICED17fullpaper.pdf (accessed 15 August 2017).

Yoon, J., Pohlmeyer, A. and Desmet, P. (2016) “'Feeling good' unpacked: developing design tools to facilitate a differentiated understanding of positive emotions', in Desmet, P.M.A. et al. (Eds.): Proceedings of the Tenth International Conference on Design and Emotion Celebration \& Contemplation, The Design \& Emotion Society, Amsterdam, pp.266-274. 


\section{Annex}

Table A1 Keywords and descriptors used to conduct online search of product examples

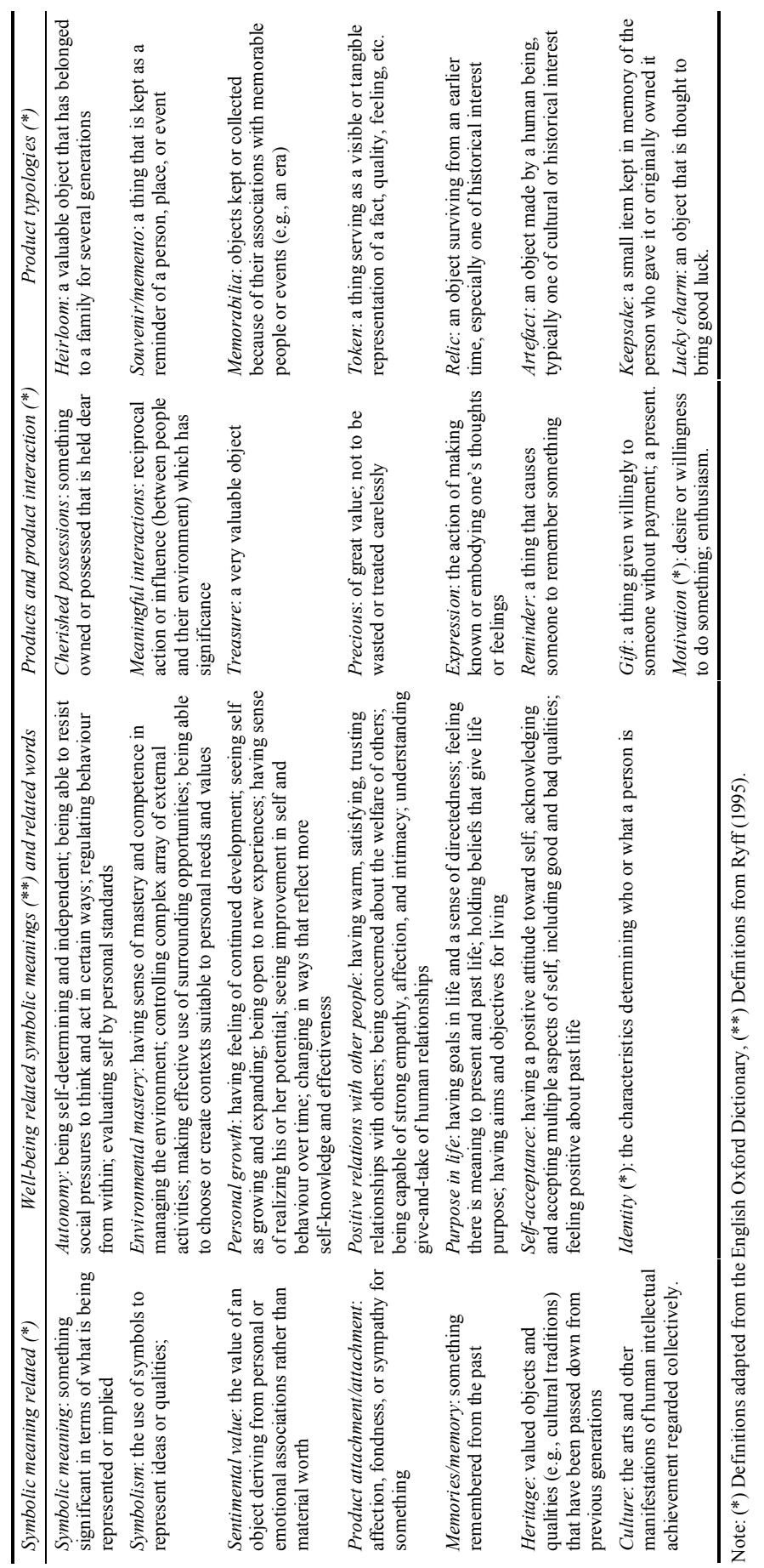

